NUREG/CR-2392

ORNL/TM-8073

OAK

RIDGE

NATIONAL

LABORATORY

UNION

CARBIDE

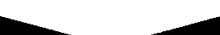

\title{
Summary of ORNL Work on NRC- Sponsored HTGR Safety Research, July 1974-September 1980
}

\author{
S. J. Ball \\ J. C. Cleveland \\ M. Hatta \\ J. C. Conklin \\ R. A. Hedrick \\ J. G. Delene \\ L. G. Johnson \\ R. M. Harrington \\ J.P. Sanders
}

IJUREG/CR--2392

DE82 008881

Prepared for the US Nuclear Regulatory Commission

Office of Nuclear Regulatory Research

Under Interagency Agreements DOE 40-551-75 and 40-552-75

OPERATED BY

UNION CARBIDE CORPOBATION

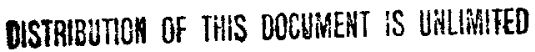

FOR THE UNITED STATES DEPARTMENT OF ENERGY 


\section{DISCLAIMER}

This report was prepared as an account of work sponsored by an agency of the United States Government. Neither the United States Government nor any agency Thereof, nor any of their employees, makes any warranty, express or implied, or assumes any legal liability or responsibility for the accuracy, completeness, or usefulness of any information, apparatus, product, or process disclosed, or represents that its use would not infringe privately owned rights. Reference herein to any specific commercial product, process, or service by trade name, trademark, manufacturer, or otherwise does not necessarily constitute or imply its endorsement, recommendation, or favoring by the United States Government or any agency thereof. The views and opinions of authors expressed herein do not necessarily state or reflect those of the United States Government or any agency thereof. 


\section{DISCLAIMER}

Portions of this document may be illegible in electronic image products. Images are produced from the best available original document. 


\title{
Printed in the United States of America. Avallable from National Technical Information Service \\ U.S Department of Commerce 5285 Port Royal Road. Springfield, Virginıa 22161
}

\author{
Avallable from \\ GPO Sales Program \\ Division of Technical Information and Document Control \\ U.S. Nuclear Regulatory Commission \\ Washıngton, D.C. 20555
}

\begin{abstract}
This report was prepared as an account of work sponsored by an agency of the United States Government Neither the U nited States Government nor any agency thereof, nor any of their employees, makes any warranty express or implied, or assumes any legal liability or responsibility for the accuracy, completeness, or usefulness of any information, apparatus, product, or process disclosed, or represents that its use would not infringe privately owned rights Reference herein to any specific commercial product, process, or service by trade name, trademark. manufacturer or otherwise, does not necessarily constitute or imply its endorsement recommendation, or favoring by the United States Government or any agency thereof The views and opinions of authors expressed herein do not necessarily state or reflect those of the United States Government or any agency thereof
\end{abstract}




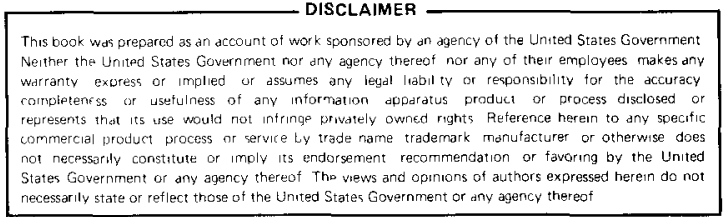

NUREG/CR-2392

ORNL/TM-8073

Dist. Category R8

Contract No. W-7405-eng-26

SUMMARY OF ORNL WORK ON NRC-SPONSORED HTGR SAFETY RESEARCH, JULY 1974-SEPTEMBER 1980

$\begin{array}{ll} & \text { S. J. Ba11, Manager } \\ \text { J. C. C1eveland } & \text { M. Hatta } \\ \text { J. C. Conklin } & \text { R. A. Hedrick } \\ \text { J. G. Delene } & \text { L. G. Johnson } \\ \text { R. M. Harrington } & \text { J. P. Sanders }\end{array}$

Manuscript Completed - February 10, 1982

Date Pub1ished - March 1982

NOTICE This document contains information of a preliminary nature It is subject to revision or correction and therefore does not represent a final report.

\author{
Prepared for the \\ U.S. Nuclear Regulatory Commission \\ Office of Nuclear Regulatory Research \\ Under Interagency Agreements DOE 40-551-75 and 40-552-75
}

NRC FIN No. B0122

Prepared by the

OAK RIDGE NATIONAL LABORATORY

Oak Ridge, Tennessee $\mathbf{3 7 8 3 0}$

operated by

UNION CARBIDE CORPORATION

for the

DEPARTMENT OF ENERGY 
-

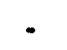

-

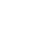


CONTENTS

Page

LISTING OF QUARTERLY PROGRESS REPORTS THROUGH FY $1980 \ldots \ldots \ldots \ldots \ldots \ldots$ v

LIST OF ACRONYMS $\ldots \ldots \ldots \ldots \ldots \ldots \ldots \ldots \ldots \ldots \ldots \ldots \ldots \ldots \ldots \ldots \ldots$

ABSTRACT $\ldots \ldots \ldots \ldots \ldots \ldots \ldots \ldots \ldots \ldots \ldots \ldots \ldots \ldots \ldots \ldots \ldots \ldots \ldots \ldots \ldots$

1. INTRODUCTION AND SUMMARY $\ldots \ldots \ldots \ldots \ldots \ldots \ldots \ldots \ldots \ldots \ldots \ldots \ldots \ldots \ldots$

2. LONG-RANGE HTGR SAFETY RESEARCH PROGRAM PLANS $\ldots \ldots \ldots \ldots \ldots \ldots \ldots .4$

2.1 Objectives of the RSR Program Plan .................. 4

2.2 Noise Analysis and Dynamic Testing $\ldots \ldots \ldots \ldots \ldots \ldots \ldots \ldots$

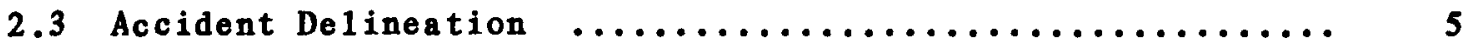

2.4 Phenomena Modeling and Systems Analysis $\ldots \ldots \ldots \ldots \ldots \ldots$

2.5 Proof Tests $\ldots \ldots \ldots \ldots \ldots \ldots \ldots \ldots \ldots \ldots \ldots \ldots \ldots \ldots \ldots \ldots \ldots \ldots$.

3. RELATIONSHIP WITH OTHER PROGRAMS $\ldots \ldots \ldots \ldots \ldots \ldots \ldots \ldots \ldots \ldots \ldots$

3.1 NRC-Sponsored Programs $\ldots \ldots \ldots \ldots \ldots \ldots \ldots \ldots \ldots \ldots \ldots \ldots \ldots . \ldots \ldots$

3.2 DoE-Sponsored Programs $\ldots \ldots \ldots \ldots \ldots \ldots \ldots \ldots \ldots \ldots \ldots \ldots \ldots \ldots$

4. SUMMARY OF ORNL PROGRAM MAJOR ACCOMPLISHMENTS $\ldots \ldots \ldots \ldots \ldots \ldots \ldots$. 7

4.1 Familiarization of Project Personne1 with HTGR

Design, Operation, and Safety $\ldots \ldots \ldots \ldots \ldots \ldots \ldots \ldots \ldots \ldots$ 7

4.2 Review of the General Atomic Codes TAP and RECA ......... 7

4.3 Independent Development of HTGR Component and System
Dynamics Codes $\ldots \ldots \ldots \ldots \ldots \ldots \ldots \ldots \ldots \ldots \ldots \ldots \ldots \ldots \ldots \ldots \ldots \ldots$

4.3.1 The ORTAP code $\ldots \ldots \ldots \ldots \ldots \ldots \ldots \ldots \ldots \ldots \ldots \ldots \ldots \ldots . \ldots \ldots$

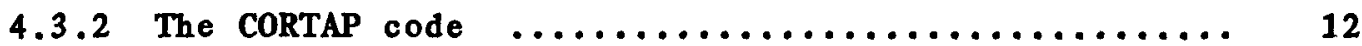

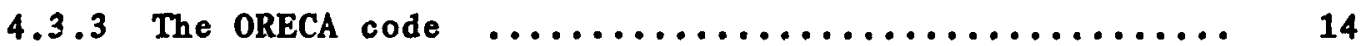

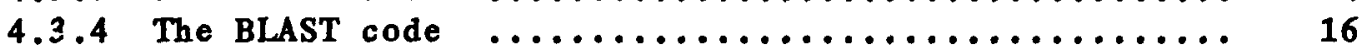

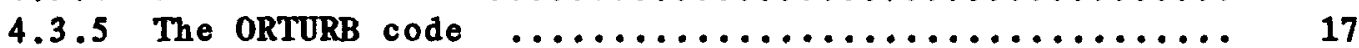

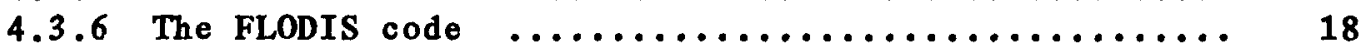

4.4 Analyses of FSV Reactivity Insertion Accidents for Comparison with FSAR Resu1ts ..................... 18

4.5 FSV Reactor Licensing Support $\ldots \ldots \ldots \ldots \ldots \ldots \ldots \ldots \ldots \ldots \ldots . \ldots \ldots$

4.5.1 NRR technical support for initial rise to

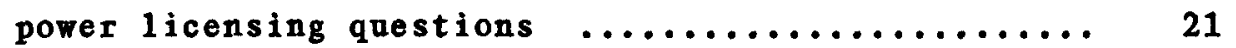

4.5.2 FSAR design-basis accident re-evaluation ......... 21

4.5.3 Investigations of the FSV oscillation problem ..... 25

4.6 Comparison of Code Predictions with Experimental Data $\ldots . .28$

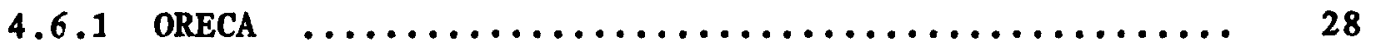

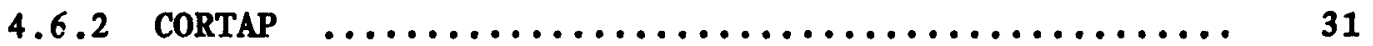

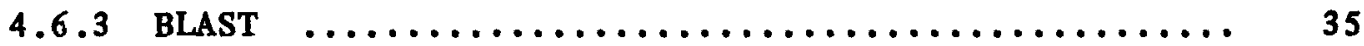


Page

4.7 HTGR Safety Information Foreign Exchange Programs ....... 36

4.8 Investigations of Overheating of FSV Upper P1enum

Cover Plates During Extended LOFC Accidents ........... 37

4.9 Calculations of Postulated FSV Reactor LOFC/FWCD Accident for Core Therma1 Stress Eva1uations .......... 41

5. HTGR SAFETY GOALS $\ldots \ldots \ldots \ldots \ldots \ldots \ldots \ldots \ldots \ldots \ldots \ldots \ldots \ldots \ldots \ldots . \ldots \ldots$

5.1 Near-Term Safety Goa 1 s $\ldots \ldots \ldots \ldots \ldots \ldots \ldots \ldots \ldots \ldots \ldots \ldots . \ldots \ldots$

5.2 Long-Term Safety Goa1s ...................... 42

5.3 Possible App1ication of an ORNL Experimental Facility, the CFTL, to HTGR Safety Problems .................. 44

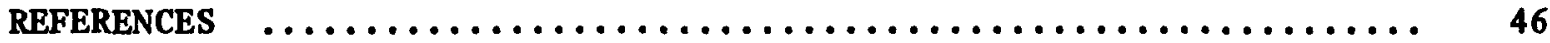


LISTING OF QUARTERLY PROGRESS REPORTS THROUGH FY 1980

Ending date

September 30, 1974

December 31, 1974

March 31, 1975

June 30,1975

September 30, 1975

December 31, 1975

March 31, 1976

June 30,1976

September 30, 1976

December 31, 1976

March 31, 1977

June 30, 1977

September 30, 1977

December 31, 1977

March 31, 1978

June 30, 1978

September 30, 1978

December 31, 1978

March 31, 1979

June 30,1979

September 30, 1979

December 31, 1979

March 31, 1980

June 30,1980

September 30,1980

\section{Designation}

ORNL/TM-4798

ORNL/TM-4805, Vo1. IV

ORNL/TM-4914, Vol. IV

ORNL/TM-5021, Vo1. IV

ORNL/TM-5123

ORNL/TM-5255

ORNL/ NUREG/TM-13

ORNL/NUREG/TM-43

ORNL/ NUREG/TM-66

ORNL/ NUREG / TM-96

ORNL/ NUREG/TM-115

ORNL/NUREG/TM-138

ORNL/ NUREG / TM-164

ORNL/ NUREG/ TM-195

ORNL/ NUREG/TM-221

ORNL/ NUREG/ TM-233

ORNL/ NUREG/TM-293

ORNL/ NUREG/ TM-314

ORNL/ NUREG / TM-336

ORNL/ NUREG / TM-356

ORNL/ NUREG/ TM-366

ORNL/NUREG/TM-383

ORNL/ NUREG/TM-397

ORNL/ NUREG/TM-415

ORNL/ NUREG/TM-429 


\section{LIST OF ACRONYMS}

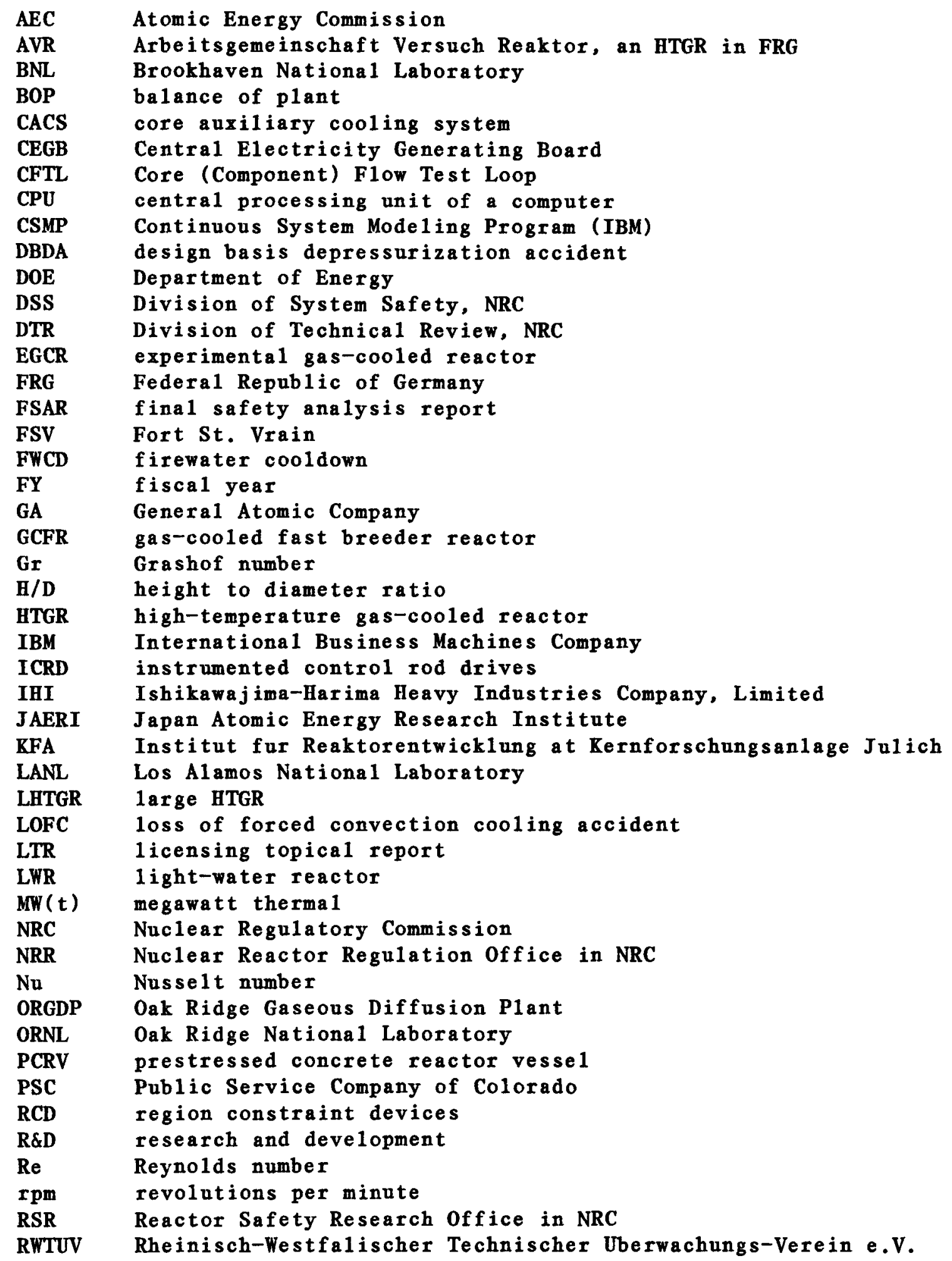




\section{LIST OF ACRONYMS (continued)}

$\begin{array}{ll}\text { SASA } & \text { severe accident sequence analysis } \\ \text { SI } & \text { Systeme Internationale (scientific units notation) } \\ \text { SNM } & \text { strategic nuclear materials } \\ \text { THTR } & \text { thorium high-temperature reactor, FRG } \\ \text { TGO } & \text { refueling region gas outlet temperature } \\ \text { UK } & \text { United Kingdom } \\ \text { 3-D } & \text { three-dimensional }\end{array}$


SUMMARY OF ORNL WORK ON NRC-SPONSORED HTGR SAFETY RESEARCH,
JULY 1974-SEPTEMBER 1980

S. J. Ba11, Manager

ABSTRACT

A summary is presented of the major accomplishments of the Oak Ridge National Laboratory (ORNL) research program on High-Temperature Gas-Cooled Reactor (HTGR) safety. This report is intended to help the Nuclear Regulatory Commission establish goals for future research by comparing the status of the work here (as well as at other laboratories) with the perceived safety needs of the 1 arge HTGR. The ORNL program includes extensive work on dynamics-related safety code development, use of codes for studying postulated accident sequences, and use of experimental data for code verification. Cooperative efforts with other programs are also described. Suggestions for near-term and long-term research are presented.

\section{INTRODUCTION AND SUMMARY}

The Nuclear Regulatory Commission's (NRC's) Reactor Safety Research (RSR)-Sponsored high-temperature gas-cooled reactor (HTGR) Systems and Safety Analysis program was initiated at 0ak Ridge National Laboratory (ORNL) in July 1974, when General Atomic Company (GA) had a number of orders to build large commercial HTGRs. Initially, the program was intended to develop an independent capability to perform and assess HTGR safety analyses that related to system dynamics and postulated accident transients. Such analyses were deemed necessary because at that time, only the vendor-developed codes were available for conducting in-depth studies of accident sequences. Other NRC-developed accident simulation codes for different reactor types were not directly applicable because of the many unique design and safety features of HTGRs.

A summary follows of the major accomplishments of the ORNL program [through fiscal year (FY) 1980]. More detailed descriptions of these items are given in the body of the report:

1. Computer codes were developed for dynamic simulation of the major HTGR system components. These codes can be run independently or combined as an overall system code. Codes were adapted to simulation of the Fort St. Vrain (FSV) reactor and, in their earlier stages, to the 2000and $3000-M W(t)$ reactor designs. The codes developed include:

a. ORTAP - an overall system code for the HTGR

b. CORTAP - core simulation for at-power transients, including point neutron kinetics and single-average-channel thermal hydraulics 
c. ORECA - core simulation for emergency core cooling transients, including three-dimensional (3-D) thermal hydraulics

d. BLAST - once-through steam generator and reheater simulation

e. ORTURB - detailed model of the turbine generator plant

f. ORCIRT - circulator turbine simulation

8. CACS - a core auxiliary cooling system (CACS) simulation was completed bat not incorporated into the overall system code because of discontinuation of the Large HTGR (LHTGR)

h. FLODIS - an a1 ternate 3-D core thermal hydraulics code developed originally under another program was refurbished for use as a backup for ORECA analyses.

2. Independent evaluations were conducted of GA dynamic simulation codes used for 1 icensing calculations, and these assessments were used by the NRC as a basis for accepting the codes.

3. Detailed analyses of reactivity insertion accidents using ORTAP were conducted and published. These analyses provided confirmation of FSV final safety analysis report (FSAR) calculations.

4. Technical support was provided to the Office of Nuclear Reactor Regulation (NRR) on licensing questions relating to the FSV initial rise to power operation.

5. The program responded to an NRR request in April 1978 for assistance in five areas relating to FSV $100 \%$-power 1 icensing questions:

a. provided audit calculations of the firewater cooldown (FWCD) and design-basis depressurization accidents (DBDA) using ORECA;

b. provided detailed calculations and parametric studies of the FWCD accident with estimates of critical component thermal histories (e.g., upper thermal-barrier cover plates) using ORECA and other codes;

c. responded to NRC questions about the ORNL review of RECA;

d. provided continuing on-call assistance in support of licensing questions;

e. informed NRC of our judgment of GA's claim that the three analyses they did in support of the 100\%-power license application (i.e., coo1down on one firewater-driven Pelton whe 1 , rapid depressurization, and permanent loss of forced circulation) did provide bounding consequences for other accidents identified within the FSAR.

6. Cooperative HTGR safety information exchange programs with Japan and The Federal Republic of Germany (FRG) were implemented that have resulted in considerable benefits to all parties.

7. Sensitivity studies were conducted in support of the accident reanalysis for FSV fu11-power 1 icensing to identify important uncertainties affecting the predictions.

8. Code verification work was done in which FSV transient data were compared with simulator predictions. Comparisons of ORECA code predictions with data from four FSV scrams indicated generally good agreement but also indicated several problem areas that led to improvements in the code and a better understanding of core transient behavior. Similar analyses were done for CORTAP using FSV rod-jog experimental data. A verification analysis was also initiated for the BLAST code using FSV and Arbeitsgemeinschaft Versuch Reaktor (AVR) data. 
9. Technical support and ad hoc analyses were provided to NRR in 1icensing-related reviews of the FSV oscillation problem.

10. Extended analyses and sma11 scale-model experiments were used to resolve 1 icensing questions relating to overheating of FSV upper-plenum cover plates by reverse or upward-flow plumes from the core during extended loss of forced-convection cooling (LOFC) accidents.

11. Technical support and analyses using the ORECA and FLODIS codes were provided to NRR in their evaluation of possible thermal stress problems in the FSV core-support regions during the cooldown following a design-basis earthquake LOFC accident.

12. A proposed experimental program was developed for FSV tests that would provide data required for critical areas of accident code verification.

A year-by-year summary of the program funding that shows both the funds received and the amount actually spent follows:

\begin{tabular}{|c|c|c|}
\hline Fisca 1 year & $\begin{array}{l}\text { Funds received } \\
\qquad(\$ 000)\end{array}$ & $\begin{array}{l}\text { Actual cost } \\
(\$ 000)\end{array}$ \\
\hline 1975 & 120 & 104 \\
\hline 1976 & 273 & 288 \\
\hline 1977 & 230 & 166 \\
\hline 1978 & 85 & 68 \\
\hline 1979 & 160 & 110 \\
\hline 1980 & 150 & 129 \\
\hline Tota $1 \mathrm{~s}$ & 1018 & 865 \\
\hline
\end{tabular}

The carry-over into FY 1981 was $\$ 153,000$.

A chronological listing of all the program's quarterly progress reports through FY 1980 also is included in this report. 


\section{LONG-RANGE HTGR SAFETY RESEARCH PROGRAM PLANS}

Two major documents elaborate on HTGR safety-re1ated research needs and recommend approaches to resolve the problems. The two documents are ORNL's Planning Guide for HTGR Safety and Safety-Related Research and Development, 1 which was published in May 1974 as a cooperative effort with GA and the Atomic Energy Commission (AEC), and an RSR/NRC draft report Program Plan for Confirmatory HTGR Safety Research, 2 issued in February 1975 .

The Planning Guide identifies specific tasks required for a comprehensive study and understanding of HTGR safety problems. It is divided into seven task areas. The first is "System and Safety Analysis," which includes primarily the types of accident sequence analyses studied in the present RSR program. The other six sections deal with specific areas of technology: fission products, primary coolant, vibration and seismic studies, confinement and containment, materials, and safety instrumentation. Detailed discussions of problem areas are given, with recommendations for programs required to solve the problems, and manpower and cost estimates are provided for each task.

The RSR program plan also presents detailed descriptions of generic problem areas, sets priorities, and recommends research programs for establishing independent assessment capabilities. Because this plan represents the basis of much of the work done in the ORNL program, an outline of the parts of the plan relevant to the ORNL program will be given, with a brief comparison of points in the plan and accomplishments by the program.

\section{2..1 Objectives of the RSR Program P1an}

The major objective of the program described by the plan is to provide independent capability for overall safety assessments of HTGRs, emphasizing the consequences to public safety of abnormal and accident conditions. A special aim is to assist NRR in its evaluation of safety problems. Needed research is divided into two categories. Topics in the category of Phenomenological Research covered by the plan are mostly addressed by research programs at other laboratories. The topic of safety instrumentation and control systems is addressed in the ORNL program in that it is related to overall systems analysis work. In the analytical research category, several topics in the plan are addressed by the ORNL program: (1) accident delineation, (2) phenomena modeling and systems analysis, and (3) proof tests. The ORNL program has assisted NRR on a number of occasions, noted in Sect. 4.5 .

\subsection{Noise Ana1ysis and Dynamic Testing}

This work is described as part of the safety instrumentation and control systems research topic (Chap. 6 in Ref. 2). The scope of this work includes (1) assessment of existing test methods, (2) determination of the feasibility of specific HTGR model verification and surveillance applications, and (3) evaluations of trial applications. Test plans for various 
model verification (but not surveillance) applications have been developed in the ORNL program, and those that have been implemented are described in Sect. 4.6. Plans have been developed but not implemented for frequency response tests (employing small perturbations in control rod position circulator speed and turbine inlet valve position) and various core mode 1 verification tests to determine bypass-flow fractions, reverse flow phenomena, and plenum mixing.

\subsection{Accident Delineation}

The objective of this task is to identify accident sequences that have potential impact on public safety and to provide descriptions or simulations of these sequences that can be used in probabilistic analyses, phenomena modeling, and systems analysis. In the ORNL program, identification, analyses, and delineation of many of the major HTGR design-basis accidents were accomplished. These efforts are discussed in Sects. 4.4, 4.5 , and 4.8 .

\subsection{Phenomena Modeling and Systems Ana1ysis}

The object of this task is to develop independent and appropriately validated analytical models and simulations that can be used for predicting HTGR system response to postulated events, including accident sequences. This task constituted the major portion of the ORNL program and is described in Sects. 4.3 and 4.6. A related task was a review of the HTGR vendor's accident analysis codes noted in Sect. 4.2 .

\subsection{Proof Tests}

The objective of the proof tests is to validate the component and system simulation codes. Work accomplished by the ORNL program in this area is described in Sect. 4.6 . 


\section{RELATIONSHIP WITH OTHER PROGRAMS}

\subsection{NRC-Sponsored Programs}

The ORNL RSR-sponsored program has benefited from collaboration and information exchanges with sister laboratory programs at Los Alamos $\mathrm{Na-}$ tional Laboratory (LANL) and Brookhaven National Laboratory (BNL). Several meetings were he1d with LANL project personnel to discuss common problems in the development of ORNL's ORTAP code and LANL's CHAP code. A recent cooperative effort with the LANL stress analysis group on the FSV core-support thermal stress problem (Sect. 4.9) resulted in a satisfactory resolution of the problem in February 1981.

Our main collaboration with BNL has been in the area of code review. A recent BNL review ${ }^{3}$ of the ORECA code was very useful and resulted in many improvements to the code, including a much more accurate treatment of the core conduction equations. We are presently looking forward to their review of the BLAST code.

We have also participated in joint efforts with other ORNL-NRC programs, particularly concerning noise analysis and diagnostics in the FSV oscillation problem studies.

\subsection{DOE-Sponsored Programs}

Close ties have been maintained with the ORNL Department of Energy (DOE)-sponsored HTGR programs. On several occasions, RSR-developed codes were used to solve specific DOE-sponsored problems in such areas as steam generator stresses and core graphite oxidation. Liaison with the advanced HTGR projects also helps in anticipating future safety requirements. 


\section{SUMMARY OF ORNL PROGRAM MAJOR ACCOMPLISHMENTS}

\subsection{Familiarization of Project Personne1 with HTGR Design, Operation, and Safety}

When the RSR-sponsored HTGR safety program began at ORNL in July 1974, only a few of the project personnel had significant experience with gas-cooled reactor design and dynamics. Collectively, however, the principal participants had gas reactor system experience with commercial HTGRs, FSV, the experimental gas-cooled reactor (EGCR), the ORNL Pebble Bed Reactor Experiment, and in-pile gas-cooled loops. Other relevant experience included core physics, power and experimental reactor dynamics, steam generator dynamics modeling, and a variety of reactor safety analyses.

Several program personnel attended a one-week course on HTGRs in September 1974 given at the University of Tennessee as a part of Tennessee Industries Week. Early in the program, participants attended several Advisory Committee on Reactor Safeguards (ACRS) and 1icensing review meetings, meetings with the HTGR vendor (GA) and major utility [Public Service Company of Colorado (PSC)], and with sister 1aboratories (LANL and BNL) engaged in HTGR safety research - all of which could be considered part of a familiarization program.

A subcontract was initiated with T. W. Kerlin of the University of Tennessee to compare the modeling and analytical solution methods in common use for once-through steam generators. Professor Kerlin had considerable experience in dynamic modeling of nuclear power plants in general and of nuclear steam generators in particular.

Another part of the familiarization program was the acquisition and review of GA's major dynamic simulation and safety analysis codes, inc1uding TAP, RECA, LAP, BLOOST, POKE, CONTEMPT-G, OXIDE-3, and others. Reviews of the key licensing topical reports (LTRs), the FSV FSAR, and a general literature survey that included earlier U.S. research and development (R\&D) and United Kingdom (U.K.) Dragon program reports were also part of the initial effort.

Since the initial familiarization process, continued close 1 iaison has been maintained with GA, PSC, and the DOE-sponsored HTGR program at ORNL. Useful interaction and some joint programs are discussed in Sect. 4.7 .

\subsection{Review of the Genera1 Atomic Codes TAP and RECA}

At the request of NRC, two of the GA dynamic simulation codes used for licensing analyses were evaluated. The evaluations of the TAP (Transient Analysis Program)s and RECA (Reactor Emergency Cooling Analysis)6 codes were based on (1) careful reviews of the reference documents and (to some extent) the coding and (2) comparisons of the results of benchmark calculations with those of other codes and with experimental data. Note that both TAP and RECA are very complex and sophisticated genera1-purpose codes. In such cases, the adequacy and accuracy of any given analysis 
depends strongly on user input, the severity of the postulated accident, and other factors that cannot be evaluated on the basis of the codes themselves. However, numerous opportunities have occurred to make direct comparisons between the GA and independently developed ORNL codes, and the agreement has been generally quite good.

In the CORTAP report, ${ }^{7}$ comparisons were made of the steady-state core temperature conditions at $100 \%$ power predicted by TAP and CORTAP, and the agreement was very good. Comparisons of steam generator responses predicted by TAP and by BLAST," which is the steam generator portion of ORTAP, showed very close agreement even though the models and solution techniques are different. Comparisons of a benchmark case for a DBDA transient are shown in Fig. 1 .

In the course of performing several accident analyses, RECA and ORECA have been run for the same set of assumed operating conditions, and the results have been in good agreement. In an analysis of the FSV DBDA in which reduced Pelton-wheel drive speeds were assumed, the RECA and ORECA results were quite close (Fig. 2) and in neither case are operating 1 imits reached. In subsequent calculations of postulated DBDA and LOFC accidents, and in predictions of measured FSV core-region outlet temperatures following scrams, the agreement between RECA, ORECA, and the data was a11 generally very good. More detailed commentaries on specific modeling assumptions, computation techniques, and the codes' susceptibility to misuse or input errors are given in a review report."

A major long-range concern about the GA code reports was the lack of a sufficiently aggressive experimental verification program. Plans for some verification tests were ontlined briefly; however, comparisons of theoretical computations with experimental data derived from "normal operating transients" are typically insufficient. Much care and planning is required to ensure against extraneous perturbations such as unexpected or unrecorded operator actions. In particular, verification of dynamic simulation codes requires that the test perturbations excite the dynamic features of the component of interest to ensure a proper measurement. We feel that PSC should pursue detailed verification plans and tests more aggressively. As the utility that owns the PSV plant, PSC would benefit from such tests by using confirmation data to (1) reduce uncertainty, (2) possibly reduce the imposed conservatism in the predictions, and (3) relax operating restrictions.

Because in a number of cases the comparisons of the GA code data with both experimental data and output from independently generated codes have been good, the credibility of the GA codes was very high. 


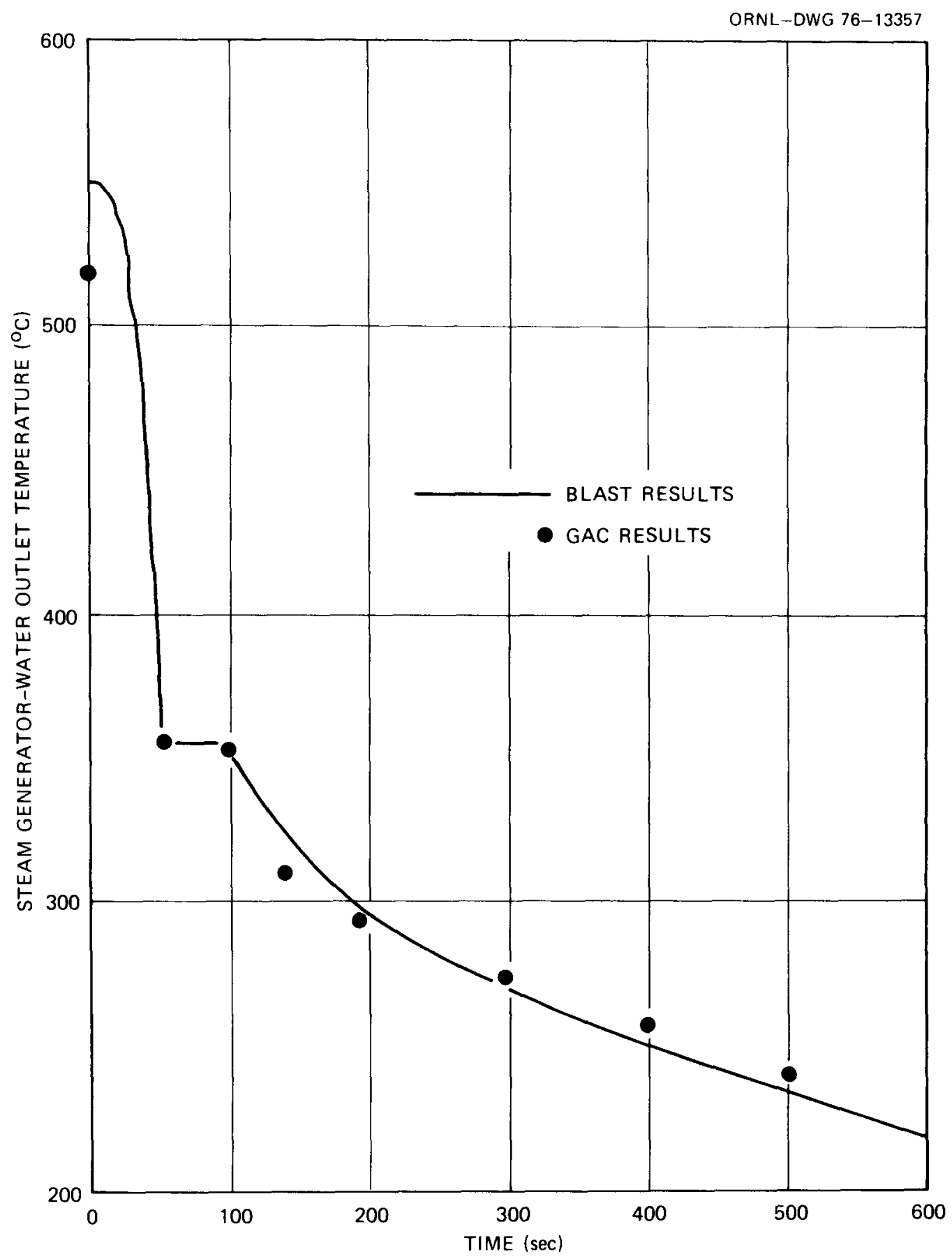

Fig. 1. Steam-generator water-outlet temperature following initiation of a DBDA $\left[{ }^{\circ} \mathrm{F}=9 / 5\left({ }^{\circ} \mathrm{C}\right)+32\right]$. 


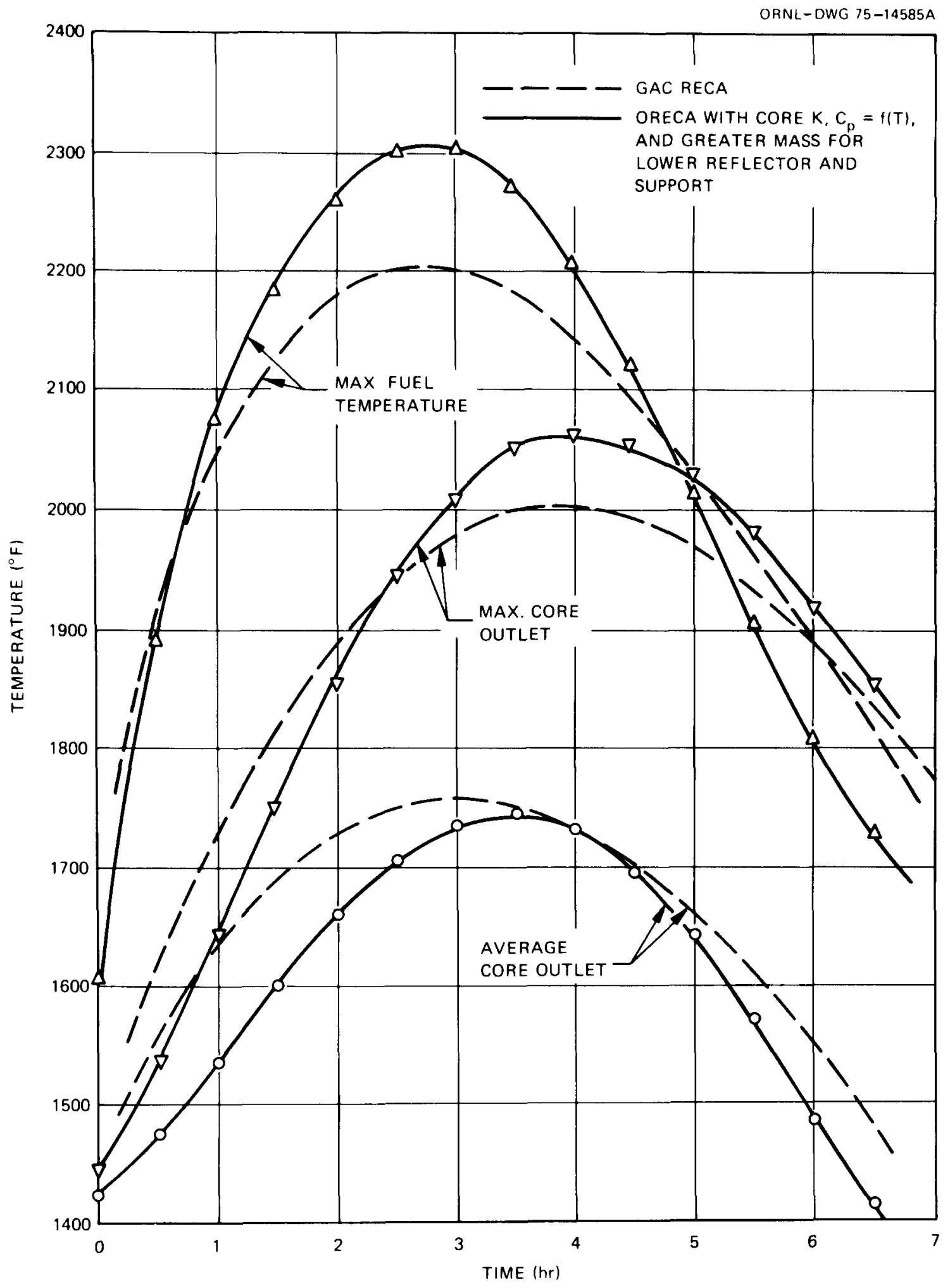

Fig. 2. Predicted system response of the FSV plant to a depressurization accident $\left[{ }^{\circ} \mathrm{C}=5 / 9\left({ }^{\circ} \mathrm{F}\right)-32\right]$. 


\subsection{Independent Development of HTGR Component and System Dynamics Codes}

\subsubsection{The ORTAP code 9,10}

The ORTAP code was developed as an independent method of predicting the dynamic response of the HTGR nuclear steam supply system to a wide range of conditions. The proprietary $\mathrm{TAP}^{5}$ code is used at GA to predict HTGR transient response. The ORTAP code contains coupled component simulations of the core (CORTAP, ${ }^{\text {ORECA }}{ }^{11}$ ), the reheater and steam generator (BLAST), the helium circulator and circulator turbine, and the balance of plant (BOP). The major plant control systems are also modeled.

The core is normally simulated by a coupled heat transfer-neutron kinetics single-channel model (CORTAP). An alternate core model (ORECA) is used for transients involving post-trip power and flow conditions. The ORECA model includes 3-D temperature distribution calculations, accounts for the varying flow distribution among the individual refueling regions, and represents flow reversals.

The reheater and steam generator are simulated with the multinode, fixed-boundary, homogeneous-flow model (BLAST). Time-dependent conservation of energy, mass, and momentum equations for both the helium side and the water/steam side are solved by an implicit integration technique. Transients involving both start-up and flood-out of the steam generator can be simulated.

A detailed model of the turbine-generator plant is necessary to accurately predict primary system component response because of the close coupling between the primary system and the secondary system. The systems are coupled by heat transfer in the reheater and steam generator. Also, the exhaust steam from the high-pressure turbine drives the helium circulator turbine before entering the reheater. Additional coupling is introduced by the plant control loops. The turbine-generator model determines pressures, enthalpies, and flows at several points, including extraction and exhaust lines in the high-, intermediate-, and low-pressure turbines. The dynamic response of each feedwater heater and the deaerator is exp1icitly treated in the model. The circulator-turbine model includes calculations of the steam-side turbine pressure, flows, and enthalpies and the helium-circulator-side pressure rise, flow, and temperature rise. The circulator turbine speed and pressure ratio controls are included.

Following the turbine trips, steam to drive the circulator-turbine is provided by the main steam bypass system, which includes a desuperheater and a flash tank. The dynamic response of these components is included in ORTAP.

The present version of ORTAP is developed specifically for the FSV plant, although with changes in input and minor program modifications, ORTAP could be used to simulate other HTGRs. The extent of the modifications required would, of course, depend on the new plant design but would not be difficult if the changes primarily involved scale-up.

Since the initial development of the ORTAP code, numerous improvements have been made that have resulted primarily from application of the 
code to specific problems. Changes have been made in the following areas:

1. Improvements were made in the turbine, feedheater, circulator turbine, and main steam bypass systems simulations that resulted in better convergence and run-time efficiency, especially for low-flow and offnormal operating conditions.12

2. A correction was made to the ORCIRT circulator turbine subroutine; this correction had 1 ittle effect on the cases run to date but would have made a significant difference for a depressurization accident.

3. Updated versions of a11 the Fortran routines were collated and put on disk files for more ready access. Work on further documentation and annotation of the 1 istings and sample transients was also done to make the code more readily exportable.

4. The code was modified to account for the 152-s rod-bank insertion time on a scram and for several variations of the minimum assumed scram reactivity available. A standard GA-supplied scram-power-vs-time curve had been used previously. In the updated version, the reactor core power derived from the kinetics equations is used until the power level falls to the point where it is equal to the standard scram curve, which accounts for afterheat. Thereafter, the scram curve is used. This modification resulted in higher predicted peak fuel temperatures for sample accident cases.

5. The ORTAP code was modified to simulate turbine-trip transients in which the reheat-steam temperature control system, which uses reactor power level as a dependent variable, functions to keep the plant operating. Several successful example turbine-trip runs were executed.

6. The circulator-turbine model (ORCIRT) was modified to simulate the turbines operating on wet steam. The main steam-bypass system subroutine was also modified to dampen the computation noise in the calculated bypass flow seen during parts of the shutdown transients.

7. Simulation of plant operation at low-power $(-25 \%)$ conditions was achieved. Substantial adjustment of control system parameters resulted in good agreement with most plant operating characteristics.

8. Improvements to several steam property subroutines and the feedwater-heater subroutine resulted in substantial decreases in computer running time for certain transients.

9. Alternative models and subroutines were developed for the steam lines in the turbine plant. The origina1 ORTAP steam 1 ine model requires small computation time steps because it uses a simple explicit integration method. This steam line time step is the smallest one and tends to 1 imit the maximum value for the overall code.

This model includes the (1) main 1 ine, (2) high-pressure turbine, (3) cold reheat steam 1ine, (4) hot reheat steam line, (5) main steam bypass 1 ine, and (6) reheat steam bypass 1 ine. In a11, five plenums are considered: the steam generator, cold reheat, helium circulator, hot reheat, and flash tank plenums. Heat and mass balances were maintained in each plenum. Turbine steam flow is calculated by a simplified turbine mode1. Pipe pressure loss is considered using a constant turbulent-flow friction factor, and pipe heat capacity is accounted for as a lump mass.

This system has about 30 state variables and therefore 30 differential equations that are coup1ed. These are solved by MATEX2, a modifica$t$ ion of the MATEXP code, 13 which accounts for full coupling of state variables. As a result, calculation time is proportional to the square of the 
number of state variables. The MATEX2 code eliminates insignificant coupling terms.

In a sample transient calculation, a time step of $0.4 \mathrm{~s}$ was applied, and the calculation (CPU) time for a 100-s turbine plant transient was 15 s on the IBM $360 / 91$.

10. The version of ORTAP in use during the past years [and as sent to Rheinisch-Westfalischer Technischer Uberwachungs-Verein e.v. (RWTUV) and Ishikawajima-Harima Heavy Industries Company, Limited (IHI)] appeared to execute properly on the ORNL computer system. However, when this version was run at the Oak Ridge Gaseous Diffusion plant (ORGDP) computer site, errors occurred. The execution errors at ORGDP were traced to the ORTAP subroutine SUPORT, which calculates the average reactor-core outlet gas temperature. The SUPORT code was modified to eliminate errors related to underflows and differences in variable initialization techniques. A few minor corrections to the subroutine logic were also implemented to account properly for coolant flow through the control-rod guide tubes.

The corrected code now executes properly at both the ORNL and ORGDP computer sites without the necessity of masking underflows. Card decks of the revised subroutine SUPORT have been transmitted to RWTUV and IHI.

The present status of the ORTAP code is that of a fully operational simulation of the overal1 FSV plant, and it has been and can be applied to a variety of postulated accident and transient studies. One of the code's major limitations is that its setup for a particular transient study usual1y requires coding changes as well as input data changes. Future deve1opment of ORTAP is p1anned to make the code more readily adaptable to a variety of prescribed transients by means of input data changes only. other efforts are planned in incorporating axiliary control-loop simulations, generally improving the code's running efficiency and developing a1ternate mode1s (e.g., a simplified core or steam generator) that more nearly match the needs of specific user problems.

Descriptions of applications of the ORTAP code to specific analyses are given in other sections of this report.

\subsubsection{The CORTAP code?}

The CORTAP code simulates the HTGR core thermal and neutronic response to normal operational transients and to postulated accident conditions. This response is determined by coupling the neutron kinetics equations to the heat transfer equations for the fuel, moderator, and coolant in a representative region of the reactor core. The model represents a unit cell consisting of a fuel stick, the surrounding graphite moderator, and coolant channels in the average power region. The code also has the capability to determine conservative values of fuel, moderator, and coo1ant temperatures in the "hot" fuel region.

The major features of CORTAP follow:

1. Up to 60 nodes can be used to represent an average or hot fuel stick, the surrounding graphite and coolant channels, the top and bottom reflector elements, and the core-support block. The model includes the temperature dependence of the fuel and moderator conductivity, density and specific heat, and the helium transport properties. Therefore, up to 60 first-order, nonlinear, inhomogeneous differential equations are used to represent the core thermal response. 
2. Heat transfer from the graphite to the coolant is calculated based on the helium flow regime (turbine-transitional-1aminar).

3. The neutron kinetics behavior of the core is modeled using spaceindependent neutron kinetics equations with six groups of delayed nentrons. The "prompt jump" approximation is not made.

4. Fue 1 and moderator temperature coefficients of reactivity are considered temperature dependent.

5. The neutron kinetics equations are coupled to the heat transfer equations through a rapidly converging iterative technique, so that correct fuel and graphite temperatures are used in determining the feedback reactivity rather than temperatures existing at the end of a previous time step.

6. A smaller computational time step is used for the solution of the neutron kinetics equations than is used for the solution of the heat transfer equations, because the response of the reactor power to reactivity changes is much faster than the response of fuel and moderator temperatures to changes in core power.

7. For transients involving a reactor trip, the core heat-generation rate is determined from an expression for power decay following a scram.

8. Input to the code includes the coolant flow rate and inlet temperature as functions of time. Axial relative power-peaking factors are input and assumed constant during transients. The time dependence of the component of the reactivity change caused by control rod motion must also be input.

9. The CORTAP code can be used alternatively as a stand-alone code for analysis of HTGR at-power core transients or as a subroutine of the ORNL overa11 HTGR plant dynamics code ORTAP.9

The CORTAP code was developed both as an aid in the evaluation of the GA system transient analysis code TAPs and as an independent method of analyzing transients affecting the HTGR core. Reference 7 describes the techniques used in the CORTAP simulations, comparisons of CORTAP results with results obtained by $G A$, input instructions, and sample input. Secion 4.6.2 of this report describes comparisons of CORTAP results with FSV transient data. The only additional follow-up work presently planned for CORTAP development is generation of an alternative simplified model that can be substituted for CORTAP (optiona11y) in the overall systems code. One version of this model has already been developed and checked out in a DOE-sponsored advanced-HTGR simulation program. However, this version uses a simulation language, Continuous System Mode1ing Program (CSMP), that is not rea1ly adaptable to ORTAP coding.

\subsubsection{The ORECA code ${ }^{11}$}

The ORECA code was developed to predict the 3-D transient therma1hydraulic behavior of HTGR cores for specified accident and emergency shutdown conditions. It was modeled after GA's RECA code to (1) provide a better understanding of the relative importance of mechanisms for afterheat removal and (2) enable independent evaluation of GA analyses. Reference 11 describes the ORECA modeling and solution techniques and examples of transient calculations. The report shows predictions of several types of accident transients to be in good agreement with the results of RECA 
calculations. The relatively small computation times required for ORECA make it convenient to use for model and parameter sensitivity studies. The original development of ORECA included three versions, one each for FSV, the 3000-MW( $t$ ) LHTGR, and the intermediate-size commercial HTGR [2000 MW $(t)]$. Most of the later development of ORECA was concentrated on the FSV version in response to specific licensing requirements.

The original ORECA code for the FSV reactor had the following characteristics and capabilities:

1. Each of the 37 refueling regions and 18 side-reflector blocks was represented by 8 axial nodes (a total of 440 nodes for the core simulation). Of each group of 8 axial nodes, 6 represented the active core, 1 the top reflector, and 1 the bottom reflector and core-support blocks.

2. Coolant heat transfer coefficient calculations included the effects of changing flow regimes (turbulent-transition-1aminar) and of he1ium conductivity and viscosity variations with temperature.

3. Inputs included total helinm flow, inlet pressure and inlet temperature vs time, and the total reactor power vs time following a typical scram curve. Input values of axial and radial power-peaking factors are assumed constant throughout the run.

4. The flow calculated for each channel depends on friction losses, acceleration losses, buoyancy effects, and empirically derived entrance and exit loss and orifice pressure drop coefficients. Calculated friction losses depend on the flow regime.

5. Channel flows are calculated at each time step by an iterative scheme that determines the overall core pressure drop and the proper total flow rate (within a specified error). Reverse flows are also accommodated.

6. To investigate the consequences of postulated LOFC accidents, a model was developed for predicting the maximum temperatures of the prestressed concrete reactor vessel (PCRV) therma1-barrier cover plates in the core-inlet plenum. In such accidents, the cover plates would be exposed to hot plumes emanating from those refueling regions in which reverse (or upward) flow occurs. This model was incorporated into the stand-alone ORECA code as an optional feature.

7. A most helpful review of the ORECA code was done by $P$. $G$. Kroeger, ${ }^{3}$ who noted some problem areas and made several good suggestions for improvement. Appropriate coding changes were made as a result. The major improvement made was to the internode heat-conduction algorithm. Previously, the effective thermal conductance between a given node and its neighbors was assumed to be a function of only that node's temperature. In the corrected version, each conductance term is based on the average temperature of the given node and its neighbor. Corrections were made to the acceleration pressure-drop term and the orifice coefficient temperature multiplier for cases in which flow is reversed. Improvements were also made in the algorithms that account for the ratios of conduction areas and directional conductivity relationships for axial vs radial conduction between refueling region blocks.

8. Because a more detailed analysis was required of the core-support region, the axial node structure was changed to include two nodes for the bottom reflector and one for the core-support block, for a total of 10 axial nodes per region. 
9. The ORECA code was used in investigations of the FSV oscillation problem ${ }^{14}$ (see also Sect. 4.5 .3 of this report). To confirm the GA jaws model for explaining the large oscillations in core-region outlet temperatures, a special version of ORECA was developed to back calculate the region flow changes that would be required to produce the observed outlet temperature perturbations. Some problems were enconntered with noise in the resulting region flow calculations because the measured temperature output is a lagged function of flow caused by both the region heat capacity and the thermocouple assembly. For both of these effects, the lower the flow, the slower the response and, thus, the more sensitive the back-calculated flow is to temperature changes. To minimize the flow fluctuations, the temperature data were fitted and smoothed using a thirdorder Lagrangian interpolator. The code was also modified so that measured and calculated steam-generator helium inlet temperatures could be compared. This feature also allowed an alternative calculation of the apparent changes in effective cold bypass-flow fraction for the 12 core sectors corresponding to each of the 12 steam-generator modules.

Further development work planned for the ORECA code includes continued mode1 enhancement based on comparisons with FSV transient data and special test results. Specific improvements planned include incorporation of a detailed PCRV 1iner cooling system simulation for modeling long-term LOFC accidents and a reworking of the input data structure so that a wider variety of transient types can be run by changing only input data. Presently, some coding changes are usually required.

Applications of the ORECA code to specific FSV licensing problems are described in Sect. 4.5, and a description of model verification efforts is given in Sect. 4.6.1.

\subsubsection{The BLAST code ${ }^{8}$}

The BLAST code simulates the HTGR reheater-stean generator module with a multinode, fixed-boundary homogeneous flow mode1. The original version of BLAST solved the time-dependent conservation of energy, mass, and momentum equations for the helium and water flow and the conservationof-energy equation for the tubing with an implicit integration technique. The code calculates helium and water temperature, pressure, and flow rate, as well as tube bulk and wall temperatures for a user-specified computational mesh of up to 20 nodes each for the water, helium, and tube sides.

The BLAST code has great flexibility for not only arbitrary computational geometry but also a variety of options for two-phase heat transfer correlations.

A copy of BLAST was sent to RWTUV in 1979. The RWTUV's plans involve the use of BLAST to analyze transients as required by the German 1 icensing process. The RWTUV also completed the BLAST model for the THTR reheater and steam generator. This model will be incorporated into a plant simulation of the thorium high-temperature reactor (THTR) by the Institut fur Reaktorentwicklung at Kernforschungsanlage Jïlich (KFA). The RWTUV also completed a model of the AVR steam generator with BLAST in preparation for BLAST verification activities that would compare the code with measured data from AVR transients. 
The RWTUV has modified BLAST significantly and has made these modifications available to ORNL. These versions include several improvements such as (1) a modification allowing a restart after the initial steadystate calculation or during the transient, (2) a modification in the subroutine for computing two-phase flow multipliers to extend the pressure range, (3) a more rapid method of solving the system of differential equations, and (4) a separate version of BLAST with input and output in SI units. Current plans are to use these versions in comparing BLAST predictions with measured data obtained from FSV for selected transients. These modifications provide very significant improvements in BLAST capability and represent considerable effort by RWTUV.

Besides the additional code verification work planned for BLAST, more development work will be done to improve the initial steady-state convergence routine and the helium and two-phase flow and heat transfer algorithms.

Discussions of comparisons made between BLAST and other code predictions and BLAST vs experimental data are given in Sects. 4.2 and 4.6.3. Additional research in the area of steam generator modeling was done under a subcontract with the University of Tennessee. ${ }^{15}$ Activities included development of (1) a few-node linear model, (2) a very detailed nonlinear mode1, and ( 3 ) model verification test plans.

\subsubsection{The ORTURB code ${ }^{16}$}

The electrical turbine and feedwater heater simulation ORTURB evolved from a model developed by Delene.17 Delene's coding had been modified for use in ORTAP; however, this modification used an excessive amonnt of computer time. Work was initiated to revise the computer simulation for the dynamic behavior of the steam turbine components so that sufficient accuracy would be obtained with minimum computer time. The present version of ORTURB ${ }^{26}$ is the result. This mode1 uses governing equations similar to those presented for Delene's original steam turbine model, but it uses a modeling and iteration scheme that minimizes floating point exponentiation, the major consumer of computer time. The ORTURB code was developed and debugged independent1y of ORTAP and therefore required the inclusion of FORTRAN statements to provide the necessary transient plant-behavior parameters. In ORTAP, these parameters are supplied by the appropriate plant component simulator.

The ORTURB code is divided into three main parts: (1) a driver subroutine that provides plant operating parameters and conditions; (2) turbine subroutines to calculate the pressure-flow balance of high-, intermediate-, and low-pressure turbines; and (3) feedwater heater subroutines. This feedwater heater mode1 is substantially modified from the feedwater heater model developed by Delene.1" The necessary steam property subroutines were taken from this same reference and modified slightly.

The ORTURB code has two important limitations: (1) the turbine shaft rotates at rated speed ( $3600 \mathrm{rpm})$ and (2) no energy or mass storage is accounted for in the high-, intermediate-, and low-pressure turbines. These limitations exclude the use of ORTURB during a turbine transient such as start-up from zero power or very light turbine flows.

Turbine transients that represented normal and upset turbine conditions were simulated with ORTURB. The calculated results were appropriate 
in a11 cases, and when plant data were available, calculated turbine conditions agreed quite well with the data.

\subsubsection{The FLODIS code ${ }^{18}$}

The FLODIS code is a 3-D therma1-flow analysis code that represents the FSV core in a very detailed fashion. Its present use to ORNL is mainly for comparison with ORECA, which is much less expensive to use. The original funding for FLODIS was provided by the Division of Technical Review, NRC.

The FLODIS code approximates each of the 31 seven-column refueling regions with 4 rectangular subregions and each of the 6 five-column refue1ing regions with 3 rectangular subregions. Therefore, FLODIS can calcu1ate both the intraregional and interregional flow distribution. The core is divided into 20 axial nodes.

The original version of FLODIS was substantially revised by D. D. Paul but not completed before he left ORNL. The revision has been debugged, and preliminary documentation has been prepared.19 Corrections for heat transfer coefficients and reactor afterheat have been modified to agree with those used in ORECA to compare results from both codes.

A paper entitled "Therma1-F1ow Performance of the Fort St. Vrain HighTemperature Gas-Cooled Reactor Core During Two Design-Basis Accidents" was presented at the American Nuclear Society/American Society of Mechanical Engineers topical meeting on Nuclear Reactor Therma1-Hydraulics held on October 6-8, 1980, in Saratoga, New York. The sensitivity of the interregional core flow distribution cansed by the position of the flow control orifices was investigated with FLODIS. The calculated results showed that the effect of temperature on helium viscosity is an important factor in the interregional and intraregional flow redistribution subsequent to both accidents.

\subsection{Ana1ysis of FSV Reactivity Insertion Accidents for Comparison with FSAR Results}

The FSV FSAR 20 discusses possible sources of reactivity accidents together with safeguards designed to prevent or limit the severity of these accidents. The discussion includes cases in which the accidents are followed by postulated failures in the safety system. Sources of reactivity accidents investigated by GA are:

1. excessive removal of control poison;

2. loss of fission product poisons;

3. rearrangement of core components, including fue1-1oading accidents;

4. introduction of steam into the core; and

5. sudden decrease in reactor temperature.

General Atomic Company concluded that the maximum reactivity insertion and the largest credible reactivity insertion rate would result from the accidental withdrawal of a control rod pair. The rod pair withdrawal accident is postulated to occur as a result of a malfunction of a control rod drive 
or an operator error resulting in unintentional removal of control poison from the core. The plant control system design allows withdrawal of only one rod pair at a time; therefore, the withdrawal of several rod pairs simultaneously is not considered credible. Furthermore, the control rod drive penetration closures are designed so that a control rod ejection accident is not considered a credible occurrence. Because the rod pair withdrawal accident leads to greater reactivity insertions and insertion rates than others 1 isted previously, detailed analyses of the other reactivity accidents are not presented in the FSAR.

To provide an independent assessment of the FSAR results and at the same time obtain comparisons for benchmark accident cases, the ORTAP code was used to analyze postulated rod pair withdrawal accidents for a variety of assumptions about reactor parameters and plant protection system response. ${ }^{21}$

An overall plant simulation was required for analysis of this accident to account for variations in core-inlet temperature and flow caused by the response of other nuclear supply system components and control system action. An overall plant simulation was also necessary to determine when certain scram signals, such as the scram on high reheat steam temperature, would be initiated.

Several important safety-related conclusions were reached as a result of the analysis:

1. The results indicated that the most severe temperature transient would occur if the accident were initiated from ful1 power at the beginning of the equilibrium cycle.

2. In a rod pair withdrawal accident, several plant control and safety systems must be inoperative for fue 1 temperatures to exceed $1600^{\circ} \mathrm{C}$. According to GA, fuel remaining below this temperature will not fail.

3. Considerably more time is required to reach the high reheat steam temperature scram setpoint than the $140 \%$-power scram setpoint. If the scram is initiated by the rise in reheat steam temperature, transients initiated by the accidental withdrawal of a maximum-worth rod pair from the half-inserted position result in earlier scrams and less severe temperature conditions than transients initiated by the accidental withdrawal of the same rod pair from the fully inserted position.

4. For the reference case, the use of lower core-heat conductance values results in the prediction of more severe core temperatures.

5. The action of the plant control system in reducing helium flow in an attempt to maintain the main steam temperature delays the reheat steam temperature scram because it reduces the rate of increase of the reheat steam temperature. This delay results in more severe peak temperatures in the core but less severe temperatures in the reheater and steam generator.

Comparisons of the results of the ORTAP and FSAR analyses indicated generally very good agreement.

For the reference case, no significant difference existed between the calculated time of scram and GA's reported value. The maximum fuel and gas temperature predictions were also in good agreement. Sample results of the study are shown in Table 1 . 
Table 1. Sample results of the FSV rod pair withdrawal accident study

\begin{tabular}{|c|c|c|c|c|c|c|}
\hline \multirow{2}{*}{ Parameters } & \multicolumn{2}{|c|}{$\begin{array}{l}\text { Reference case } \\
\text { RHST scram }\end{array}$} & \multicolumn{2}{|c|}{$\begin{array}{l}\text { 140\%-power } \\
\text { scram }\end{array}$} & \multirow{2}{*}{$\begin{array}{l}\text { Rods initially } \\
\text { half inserted } \\
\text { power scram }\end{array}$} & \multirow{2}{*}{$\begin{array}{l}\text { Core } \\
\text { conductances } \\
\text { increased } 50 \% \\
\text { RHST scram }\end{array}$} \\
\hline & ORTAP & FSAR & ORTAP & FSAR & & \\
\hline Time at scram initiation, s & 102.5 & 105 & 39.2 & & 76.2 & 98.3 \\
\hline $\begin{array}{l}\text { Power level at scram initia- } \\
\text { tion, } \%\end{array}$ & 282 & & 140 & & 210 & 291 \\
\hline $\begin{array}{l}\text { Maximum core average fue } 1 \\
\text { temperature, }{ }^{\circ} \mathrm{C}\end{array}$ & 1195 & 1225 & 861 & 870 & 1098 & 1147 \\
\hline $\begin{array}{l}\text { Maximum mixed mean core } \\
\text { outlet temperature, }{ }^{\circ} \mathrm{C}\end{array}$ & 994 & 1062 & 804 & 796 & 927 & 993 \\
\hline $\begin{array}{l}\text { Region experiencing with- } \\
\text { drawal: peak fuel center- } \\
\text { line temperature, }{ }^{\circ} \mathrm{C}\end{array}$ & 3057 & 2870 & 1137 & 1183 & 2082 & 2981 \\
\hline $\begin{array}{l}\text { Peak region outlet tempera- } \\
\text { ture, o } \mathrm{C}\end{array}$ & 1654 & 1650 & 862 & 914 & 1224 & 1604 \\
\hline
\end{tabular}




\subsection{FSV Reactor Licensing Support}

\subsubsection{NRR technical support for initial} rise-to-power licensing questions

A variety of relatively small tasks were done by project personnel to assist with licensing tasks both for FSV and for generic 1icensing questions in the 1974-77 period. These tasks include:

1. review of various GA LTRs,

2. Summit reactor 1 icensing review,

3. study of the effects of derating the Pelton-wheel circulator drive performance during a DBDA,

4. extension of the ORECA models to calculate heat-up of concrete near the PCRV 1 iner during an extended LOFC event,

5. studies relating to the FSV moisture ingress problem,

6. review of predicted vs measured performance of the primary circulator,

7. response to a Division of System Safety, NRC request to provide information on anticipated accident transients,

8. a study of the FSV 2-1oop dump incident,

9. a study of the control rod overheating problem, and

10. a review of emergency depressurization procedures.

\subsubsection{FSAR design-basis accident reevaluation}

In April 1978, ORNL was requested by NRC to provide independent ca1culations of both DBDA and LOFC accidents to assist in evaluating a $100 \%-$ power operating 1 icense application for FSV. Reactor operating parameters were supplied by $G A$, and worst-case equilibrium core conditions were assumed for the reference analyses. Some cases were also run using initial core nuclear parameters to evaluate consequences of a postulated LOFC accident occurring before installation of planned pumping capacity that would be used in the subsequent cooldown.

4.5.2.1 Design-basis depressurization accident. The reference case DBDA analysis using ORECA assumed a 5-min delay in the start-up of the emergency cooling system and then assumed the availability of only one loop (two of the four circulators).

of primary concern with the DBDA is the overheating of the steel 1 iners and ducting to the steam generators. This outweighs the concern for fuel damage because peak predicted fue 1 temperatures are we 11 below $1600^{\circ} \mathrm{C}$. Calculation of the steel liner temperatures is complicated primarily by uncertainties in the estimates of "streaking factors," which re1ate the maximum gas temperatures impinging on the liners to the maximum refueling-region gas exit temperatures. Using a conservative value of the streaking factor derived from GA air model tests, the predictions indicated that the $1093^{\circ} \mathrm{C}$ damage 1 imit would not be reached. Figure 3 shows some results of the reference-case ORECA predictions. Sensitivity studies were also performed to determine the effects of various assumptions on peak temperatures, and no surprises were encountered. Table 2, which gives comparisons of ORECA results with those generated by GA (RECA3 


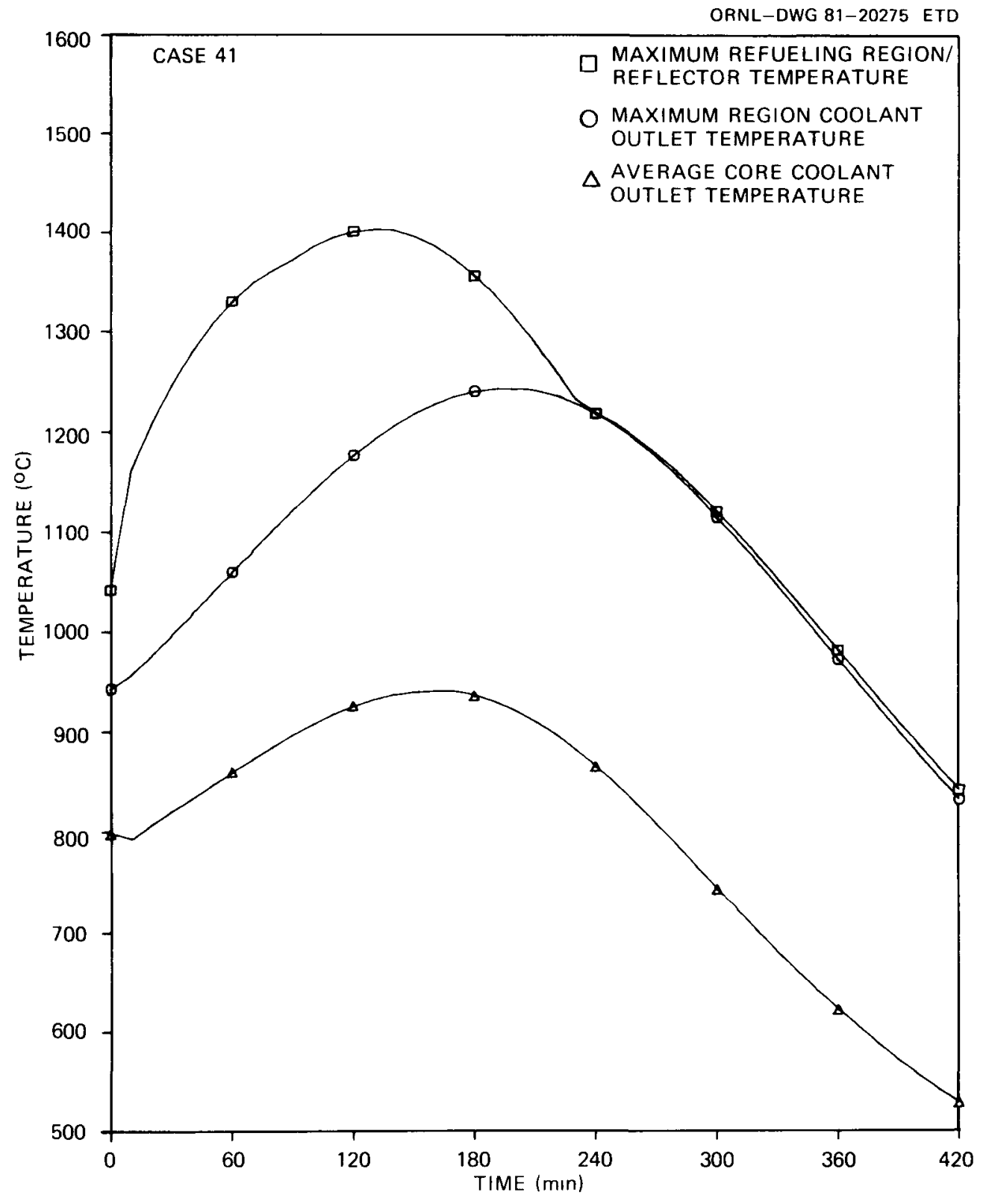

Fig. 3. Sample results of a postulated FSV reactor DBDA using the ORECA code. 
Tab1e 2. Results of FSV DBDA study

\begin{tabular}{ccc}
\hline Reference DBDA & GA/RECA3 & ORNL/ORECA \\
\hline $\begin{array}{l}\text { Peak fuel temperature, }{ }^{\circ} \mathrm{C} \\
\text { Maximum average core }\end{array}$ & $\sim 1427$ & 1403 \\
outlet temperature, ${ }^{\circ} \mathrm{C}$ & & 927 \\
Maximum refueling-region & $\sim 1288$ & 1243 \\
outlet temperature, ${ }^{\circ} \mathrm{C}$ & & \\
\hline
\end{tabular}

code), indicates generally good agreement. Note that FSAR afterheat equations were used in both analyses.

4.5.2.2 LOFC - firewater cooldown (FWCD) accidents. The LOFC accident calculations centered on the question of how much time the operators would actually need to start up the emergency cooling system following a postulated design-basis earthquake. In this case, an LOFC is followed by use of the earthquake-proof firewater system to provide both the motive force for the circulator's Pelton-wheel drives and the cooling water for the steam generators. Calculations were done both for worst-case initial and equilibrium cores, the latter giving the higher peak temperatures.

The main concern during the LOFC period is the ability of the carbon steel upper-plenum therma1-barrier cover plates to withstand the heat from the hot plumes that emanate from refueling regions experiencing reverse flows. Calculations were done for postulated delays of up to $2 \mathrm{~h}$ in initiation of the FWCD system. Subsequent analyses by NRC indicated that the assumption of a 1.5-h delay was sufficiently conservative. A major uncertainty in the model is the effective plume heat transfer coefficient ( $h$-plume), and a detailed model of the plumes and cover plates was added to the ORECA code. Depending on h-plume assumptions, the calculations indicated that some of the cover plates would be likely to exceed failure 1 imit temperatures for extensive LOFC periods.

The major problem following initiation of the FWCD system is, 1 ike the DBDA, possible damage to the steam generator inlet ducts. As before, using the GA-derived streaking factor, the damage 1 imit was not exceeded for any of the cases analyzed.

Sample results of an LOFC/FWCD ORECA calculation are shown in Fig. 4, and comparisons with some GA results for the case of no delay in initiation of FWCD (as in the FSAR) are shown in Table 3 . As in the case of the DBDA analyses, the comparisons are generally very good.

4.5.2.3 Evaluation of bounding consequences of other FSAR-postulated accidents. The FSAR's major accident scenarios include consideration of reactivity insertion accidents, loss-of-heat removal capability accidents, and chemical reaction accidents from air or water ingress.

A thorough study was made of the reactivity accidents, 21 and a followup study22 showed that while fuel damage would probably not occur, some verification data analyses should be done to check the BLOOST/CORTAP-type code accuracy. Another point that was raised by the analysis was that if the main steam-temperature control system were in manual, significant overheating of the steam generators could result [providing that several levels of defense failed (see Sect. 4.4)]. 


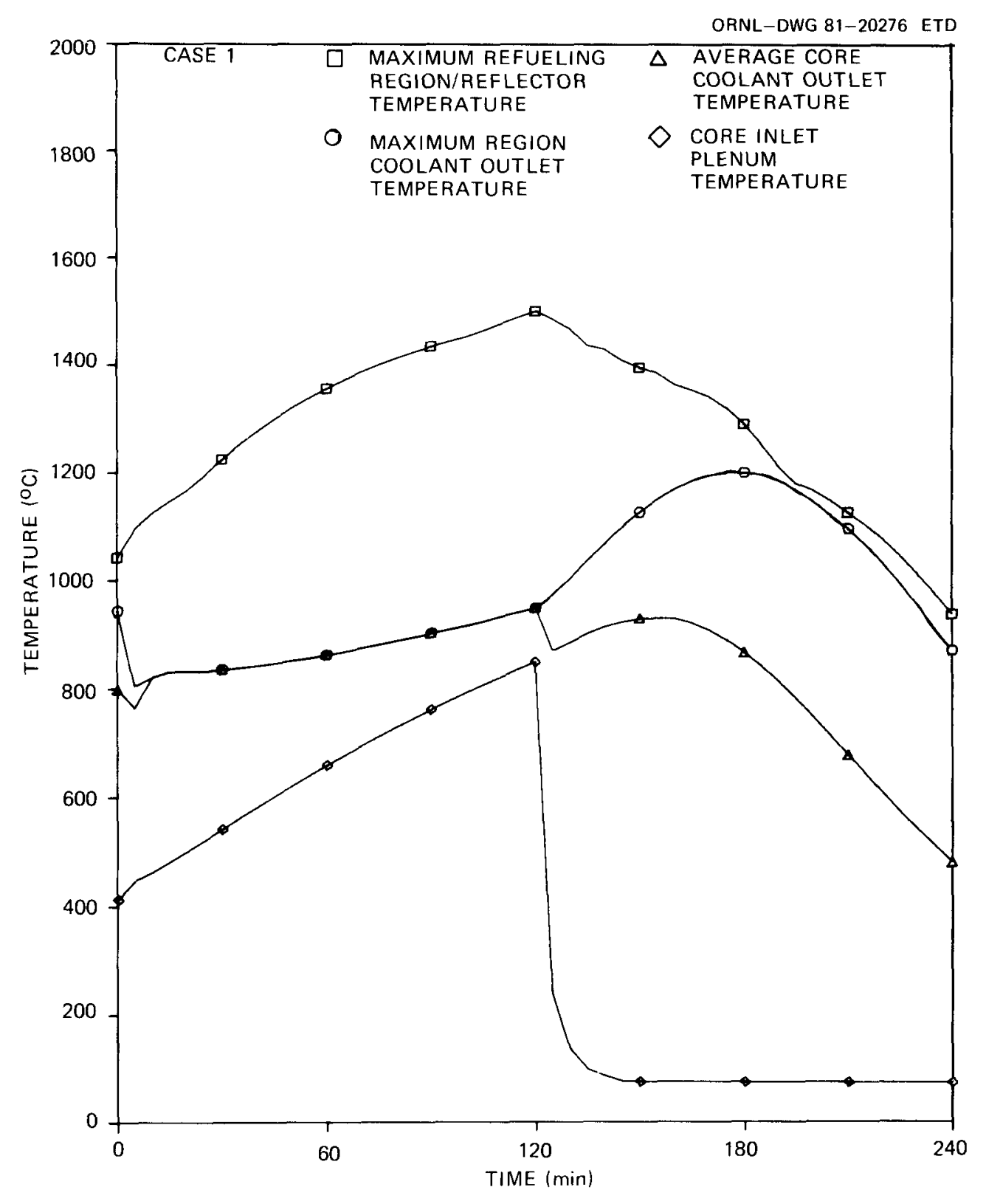

Fig. 4. Sample results of a postulated FSV reactor LOFC-FWCD accident using the ORECA code.

The failure of heat removal capability was investigated by $J$. P. Sanders, ${ }^{23}$ who addressed the problems of heat removal from the core in the event of (1) depressurization and total LOFC or (2) a permanent LOFC without depressurization. Such scenarios result in eventual deterioration of PCRV integrity, which would be especially unattractive if the reactor has not been successfully depressurized.

In summary, the scenarios that go beyond the severities of the FSAR assumptions are those that would be addressed in the severe accident sequence analysis (SASA) studies noted in Sect. 5. 
Table 3. Results of FSV LOFC/FWCD study

\begin{tabular}{|c|c|c|}
\hline Zero-de1ay FWCD & GA/RECA3 & ORNL/ ORECA \\
\hline \multicolumn{3}{|l|}{ Equilibrium core } \\
\hline $\begin{array}{l}\text { Maximum average core outlet } \\
\text { temperature, o } \\
\text { Maximum refueling region } \\
\text { outlet temperature, }{ }^{\circ} \mathrm{C}\end{array}$ & $\begin{array}{l}\sim 829 \\
\sim 1038\end{array}$ & $\begin{array}{l}821 \\
1023\end{array}$ \\
\hline \multicolumn{3}{|l|}{ Initial core } \\
\hline $\begin{array}{l}\text { Maximum average core outlet } \\
\text { temperature, }{ }^{\circ} \mathrm{C}\end{array}$ & $\sim 816$ & 804 \\
\hline $\begin{array}{l}\text { Maximum refueling-region } \\
\text { outlet temperature, }{ }^{\circ} \mathrm{C}\end{array}$ & $\sim 1038$ & 1038 \\
\hline
\end{tabular}

\subsubsection{Investigations of the FSV oscillation problem}

At the request of NRC, project personnel became involved in assessing the unique safety and licensing questions that came up because of the oscillations observed in the FSV core temperature and neutron detector measurements. At certain operating conditions, fluctuations in individual neatron channels would be as much as $\pm 5 \%$, and helium temperature excursions from individual refueling regions and to steam generator modules would be as 1 arge as 200 and $100^{\circ} \mathrm{F}$, respectively. F1uctuations could be initiated at higher levels of power and core flow resistance (which can be adjusted by the refueling-region orifice valves) and terminated by reducing the power and flow. The fluctuations had a random character, but a dominant periodicity of $\sim 10$ min was observed in many instances.

The oscillations first occurred on oct. 31,1977 , and they have since occurred at power levels ranging from 30 to $68 \%$. Tests run during both Cycles 1 and 2 have resulted in just over $100 \mathrm{~h}$ spent in an oscillation mode. Subsequent insta11ation of region constraint devices (RCDs) to the top layer to plenum elements during the October-November 1979 outage appears to have been successful in stopping the oscillations for power levels up to $70 \%$; however, more tests at higher powers are planned for 1981 .

The ORNL involvement in the oscillation problem included (1) technical support during the initial stages of analysis, (2) assessment of related safety analyses and test program plans by GA and PSC, (3) noise analyses of various core instrumentation signals, (4) review of the special in-core instrumentation [Instrumented Control Rod Drives (ICRDs)], and (5) safety assessments of the proposed fixes, including the RCDs. Program involvement is continuing through the post-RCD tests and 70 to $100 \%$ power tests.

The program's major analytical effort was an evaluation of the $j a w s$ theory, which postulated that periodic tilting of fuel element blocks near the top of the core will open up alternate flow paths through the jaws so 
formed (Fig. 5) and that the resulting additional flow through a region's coolant channels conld cause a substantial and rapid decrease in its outlet temperature. ${ }^{14}$

General Atomic postulated that the largest temperature fluctuation observed in the most significant oscillation event (November 4, 1978, $\sim 0410 \mathrm{~h}$ ) could have been caused by a $38 \%$ change in the region flow and that such a flow change was compatible with the jaws model.

To confirm the $j$ aws mode1, the ORECA code 11 was modified to take the 37 measured refueling-region outlet temperatures, the reactor power, the core differential pressure $(\Delta P)$, and the core inlet temperature vs time as input. The 37 region flows (and effective orifice coefficient changes equivalent to the jawing) vs time would then be back calculated as required to produce the observed outlet temperature perturbations.

Refueling-region (measured) outlet temperatures for the 20-min period beginning at $0410 \mathrm{~h}$ on November 4 are shown in Fig. 6 for regions 12 and 13, the two most active regions. Region 12 temperature increases $\sim 90^{\circ} \mathrm{C}$ $\left(160^{\circ} \mathrm{F}\right)$, while that for adjacent region 13 drops $\sim 100^{\circ} \mathrm{C}\left(180^{\circ} \mathrm{F}\right)$. Figure 6 also shows the results of the modified ORECA calculation of the measured

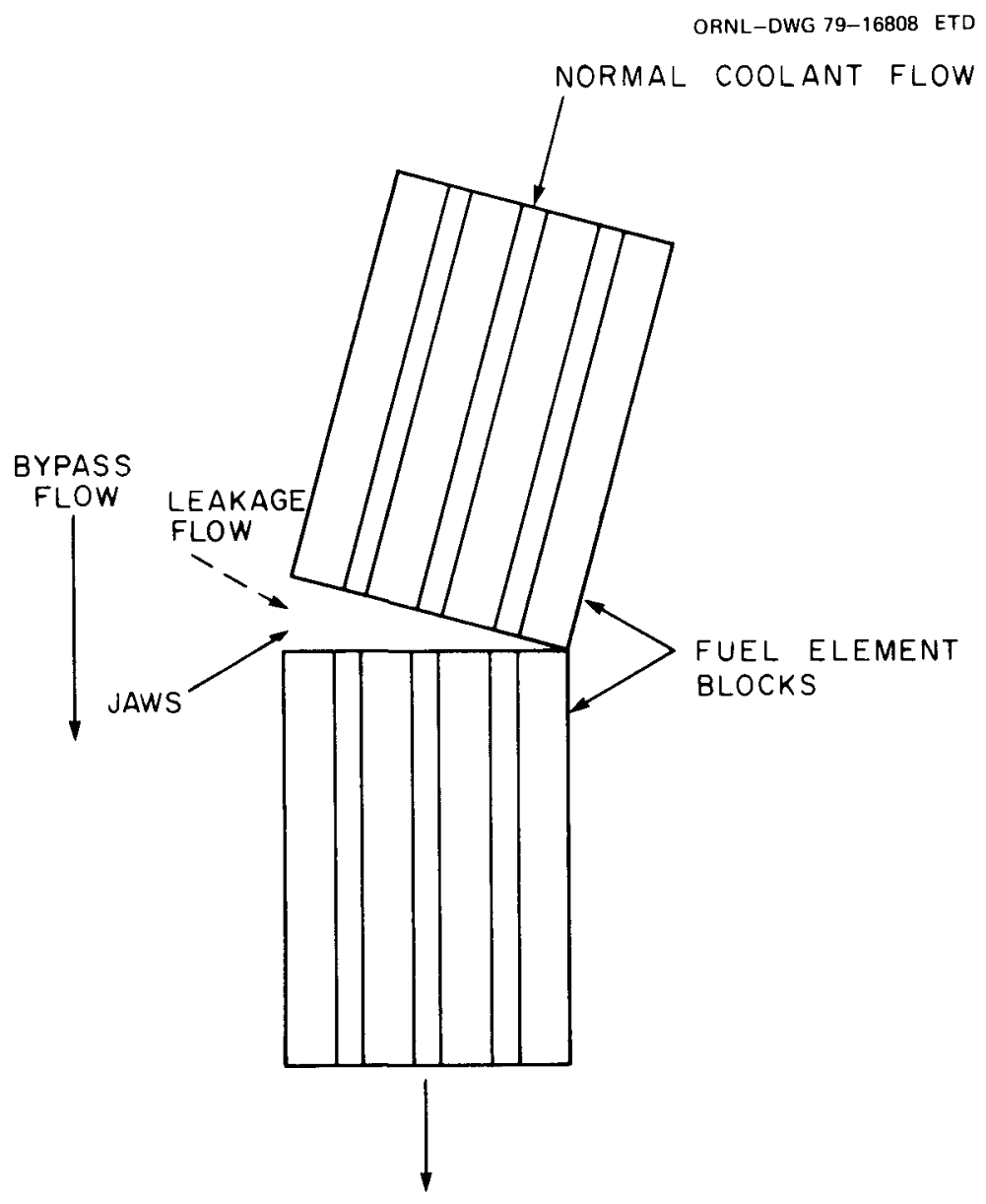

Fig. 5. Jaws theory mode1. 


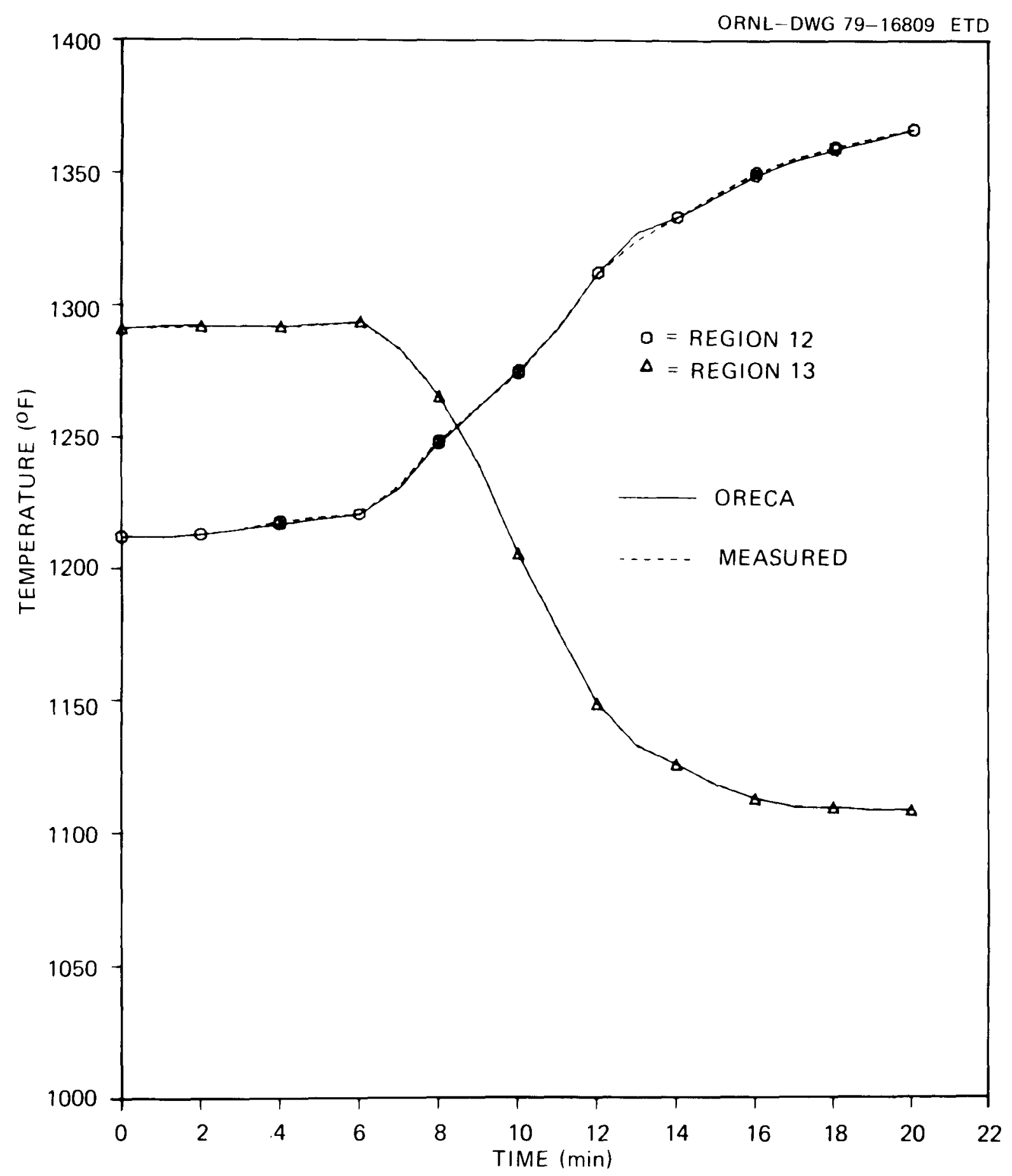

Fig. 6. Calculated vs measured FSV core outlet temperature from regions 12 and 13 during oscillation transient. Nov, 4, 1978, $0410 \mathrm{~h}$. 
outlet temperature transients (dashed curves), indicating that the back calculations of those region flows succeeded in matching the observed temperatures. The back-calculated flows for regions 12 and 13 are shown in Fig. 7. A flow increase of $\sim 70$ to $80 \%$ was needed to cause the rapid drop in temperature for region 13, and a flow decrease of $\sim 50$ to $75 \%$ was required to give the large temperature increase in region 12 . Note that the erratic nature of the region 12 flow is probably partially caused by the sensitivity of the calculation to abrupt changes in temperature slope. The measured temperature "output" is a lagged function of flow caused by both the region heat capacity and the thermocouple assembly time constants. For both of these effects, the lower the flow, the slower the response and, thus, the more sensitive the back-calculated flow is to temperature changes. To minimize the flow fluctuations, the temperature data were fitted and smoothed using a third-order Lagrangian interpolator. Even so, the flows shown are probably more erratic than would actually be required to produce the observed temperature swings. Some of the other regions with much smaller outlet temperature fluctuations also had very large computed flow transients.

In summary, sufficient uncertainties were noted in the accuracy of the data, the ORECA mode1s, and the method used to back calculate region flow transients to make any conclusion for this analysis tentative. The ORECA-derived flow variations of $\pm 75 \%$, however, are probably larger than could reasonably be expected from jaw-type leakage; thus, the assumption that other phenomena are also influencing the behavior of the region outlet thermocouples is suggested. The conclusion was made that the most likely phenomenon is the biased readings caused by bypass-flow leakage into the thermocouple assembly sleeve. Measurements support the contention that this effect would be more pronouned in regions near the side reflector.

\subsection{Comparisons of Code Predictions with Experimental Data}

\subsubsection{ORECA $^{11}, 24$}

Most of the experimental verification efforts to date have been comparisons of ORECA code predictions with data from FSV scrams. Four different scrams from power levels between 30 and $50 \%$ have been used. General Atomic Company has supplied the necessary input data, including circulator inlet temperature, core flow, pressure, and power (afterheat) vs time after the scram. The initial conditions are the 37 measured refue1ing-region outlet temperatures and estimates of each region's power-peaking factor. Comparisons are then made of the computed and measured outlet temperature transients for all regions. Although no unique combination of models and parameters exists that will produce a good fit to the data (and therefore no guarantee that an optimized model is valid), optimization schemes do suggest areas that may need improvement.

The original ORECA best-estimate calculations of the scram tests were usually in reasonably good agreement with the data; however, there were some significant differences. In Fig. 8, a typical ORECA prediction of measured region outlet gas temperature (TGO) is seen to be 1 ow after 20 to 


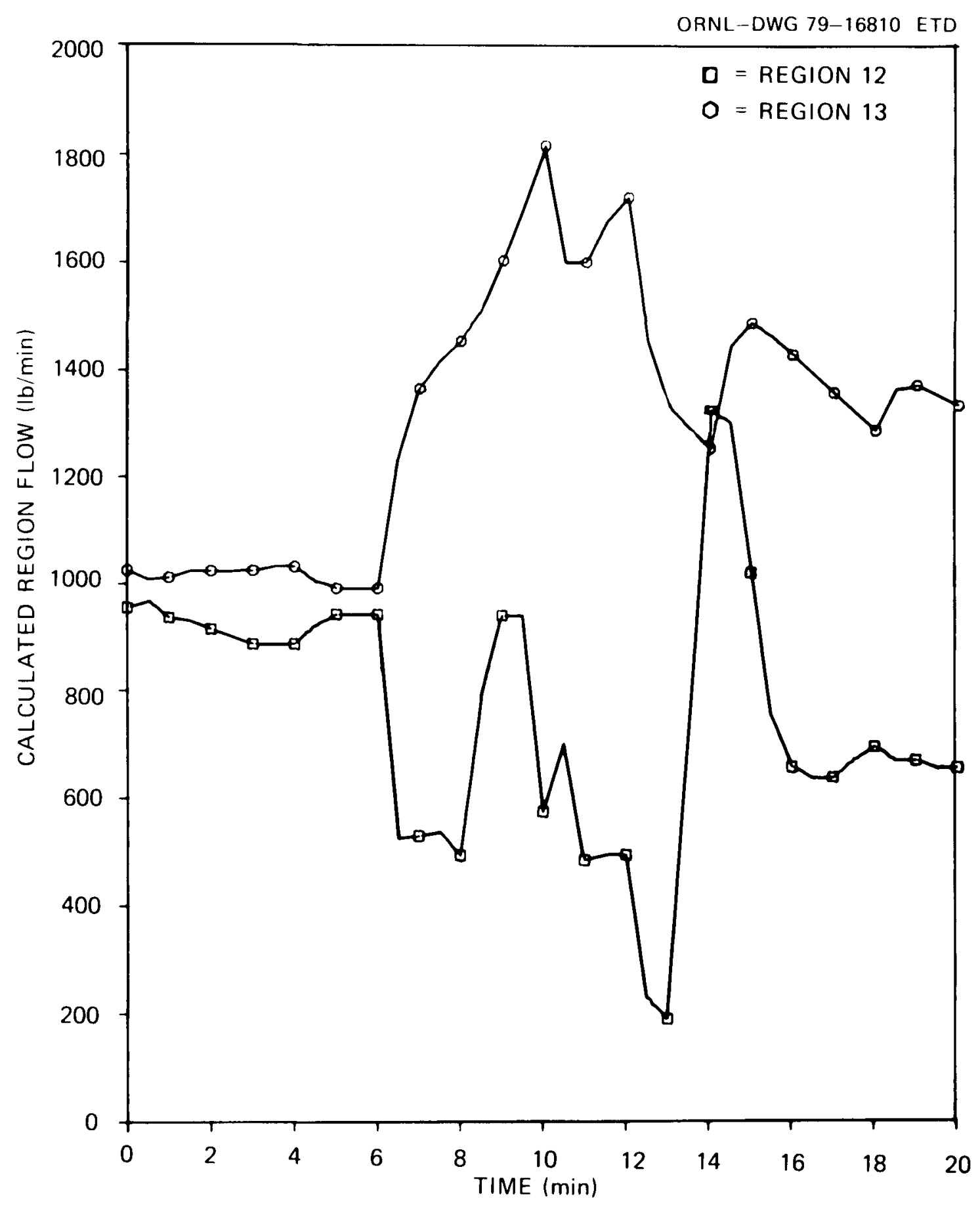

Fig. 7. Calculated FSV core flows for regions 12 and 13 during oscillation transient. Nov. 4, 1978, $0410 \mathrm{~h}$. 


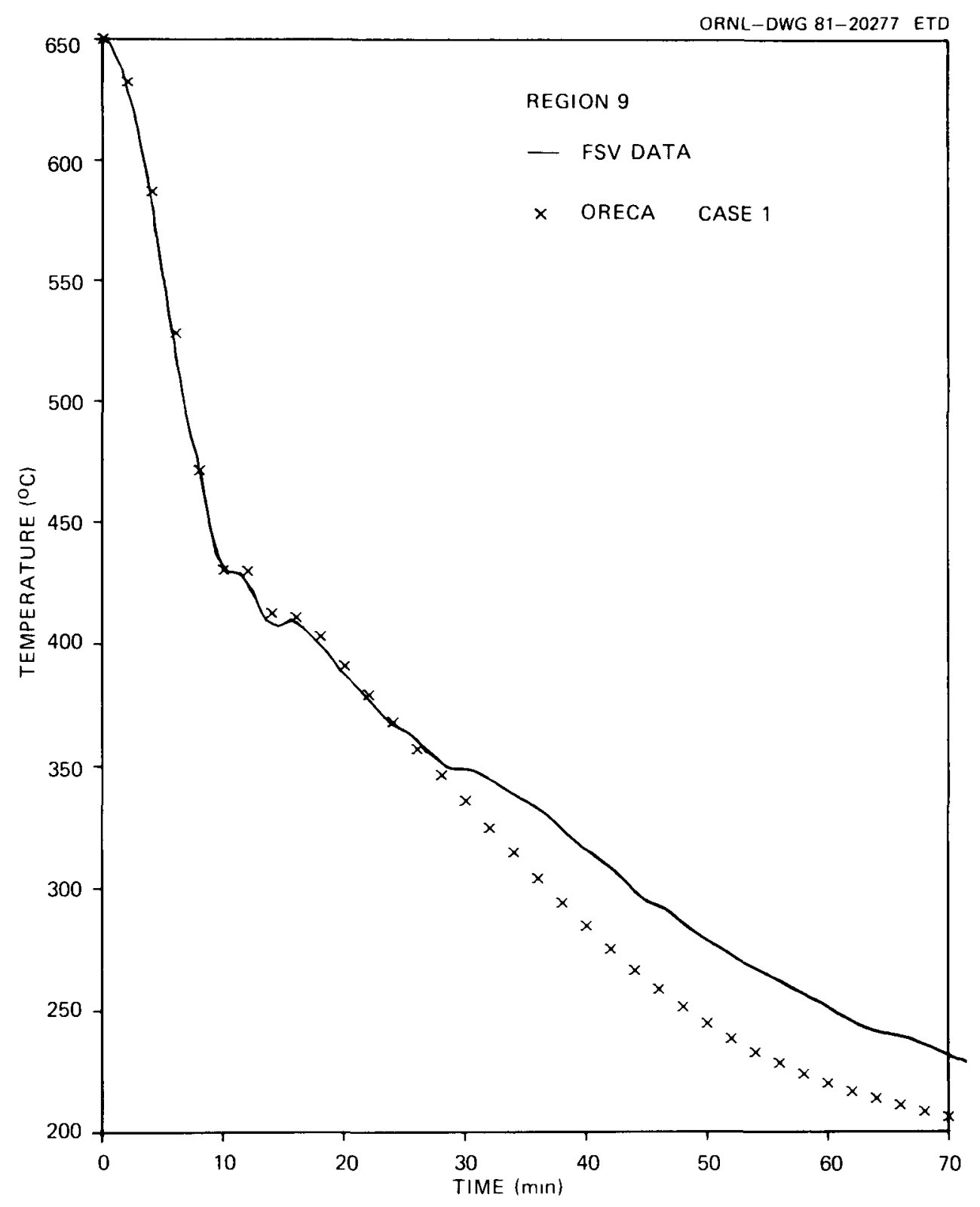

Fig. 8. FSV scram test of Aug. 6, 1977, from 28\% power - comparison of best-estimate reference ORECA code predictions of measured gas outlet temperature from region 9 vs plant data.

30 min following the scram. This has been attributed both to an overestimate of core flow (or underestimate of bypass flows) and to deficiencies in the original dynamic model of the TGO thermocouples.

The core bypass flows include those through gaps in the refueling region and side reflector block as well as flows bypassing the core barre 1 entirely. None of these is directly measurable. 
The TGO thermocouples are in large graphite sleeves and have time constants of $\sim 2$ min at rated conditions. Several versions of the thermocouple model have been used subsequent1y, with the most significant improvement being the addition of $\mathrm{T}^{4}$ radiation effects. To properly account for these effects, however, ORECA had to be revised to model the lower part of the core-support blocks separately (rather than lumped with the lower reflector as before), because the support blocks cool down much more slowly after a scram than does the rest of the core.

Other modifications required to produce a good fit were adjustments in the assumed peaking factors for many of the regions, especially those near the outer ring, and adjustments of the assumed temperature rise of the helium between circulator inlet (measured data) and the core inlet. This rise is caused by both the heat of compression from the circulators and by heat transfer to structures between the circulators and the core inlet plenum.

An optimization code was used to find the ORECA parameters that give the best least-squares fit to the data. The optimization code uses the differences in the responses generated by ORECA for several selected parameter-variation cases. By comparing these responses with the FSV data, the optimization code computes a set of optimized parameters. This set is 1 imited by what are judged to be reasonable uncertainty ranges. After these parameter adjustments are incorporated into the ORECA code, the agreement is generally excellent, with typical results shown in Fig. 9. One discrepancy still remaining (especially in the higher-power tests) is a distinct difference in the shape of the curve for several regions adjacent to the side reflector (Fig. 10). These differences are thought to be a result of interactions with the side reflectors that are not yet explicitly modeled. Work on the optimization is still in progress.

\subsubsection{CORTAP ${ }^{7}, 25$}

The CORTAP code calculates the reactor power and representative fue1, moderator, and coolant temperatures. Inputs are (1) coolant temperature, (2) flow and pressure at the core inlet, and (3) contro1-rod reactivity. The CORTAP code was used here as an independent calculation of core response rather than as a subroutine of the plantwide simulation ORTAP.

The CORTAP code calculation of reactor power transients resulting from contro1-rod movement was verified by comparison with operating data taken during control-rod influence tests at FSV. Each of the tests consisted of a brief control-rod insertion or withdrawal followed by constant control-rod position throughout the remainder of the test. The two transients used were a $6-s$ withdrawal of region 1 control rods and a nominal 24-s insertion of region 6 rods, where the contro1-rod speed was $2.5 \mathrm{~cm} / \mathrm{s}$ in both cases. Contro1-rod worths were such that a $15-\mathrm{cm}$ change in the region 1 control-rod position changed reactivity more than the $61-\mathrm{cm}$ change in region 6 rod position.

The reactor power transient was recorded for each of the six neutron detectors. Data from the six detectors were averaged for comparison with the CORTAP calculation of reactor power response. No attempt was made to compare region outlet temperatures with CORTAP calculations, because the time response of these thermocouples is not known with sufficient accuracy. 


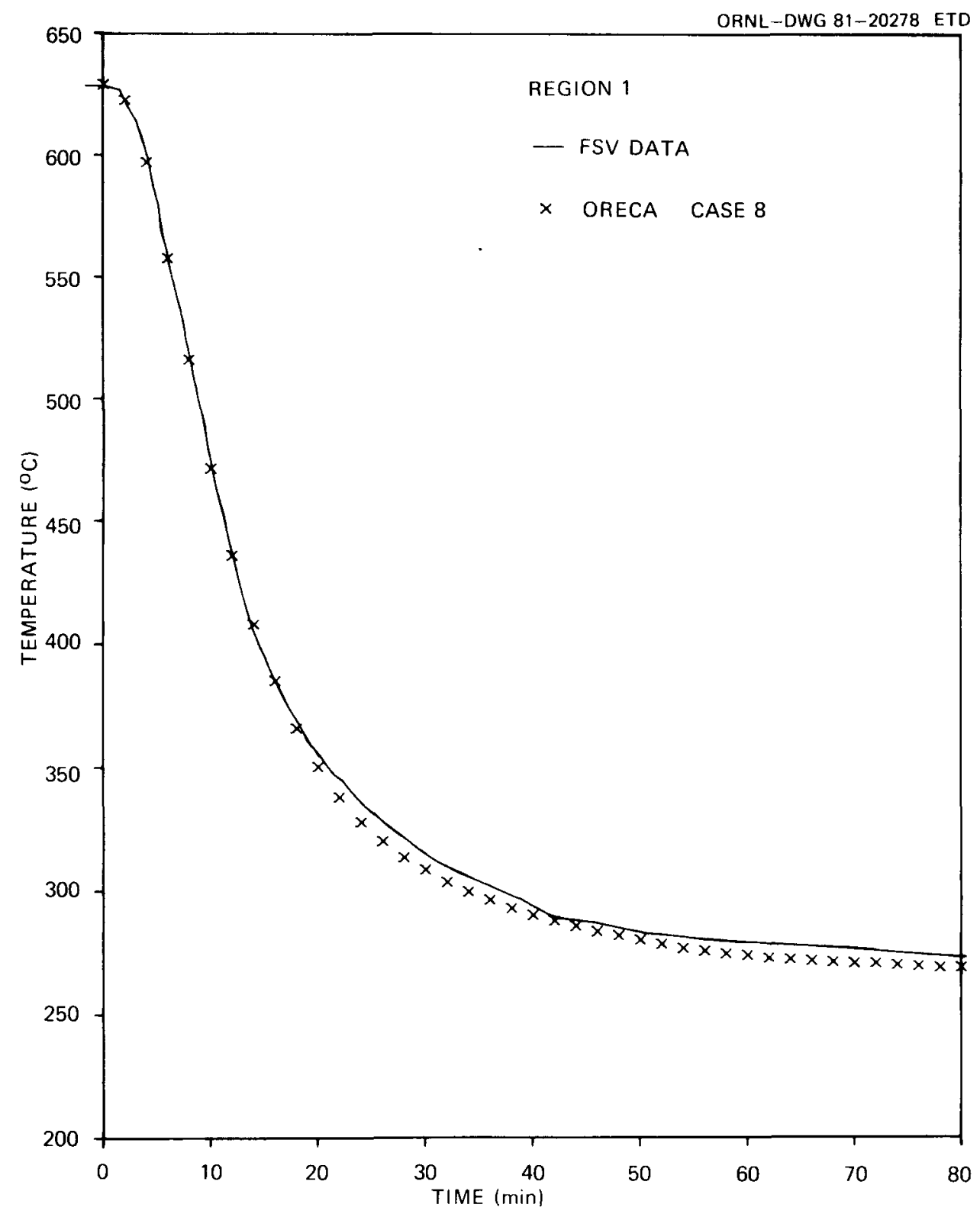

Fig. 9. FSV scram test of 0ct. 25, 1977, from 40\% power - comparison of optimized ORECA code predictions of measured gas outlet temperature from region 1 vs plant data.

The important CORTAP input parameters that were used are summarized in Ref. 25. To get a good comparison with the data (January 1978), beginning-of-cycle (BOC) inita1-core kinetics data were used. Core flow was calculated from steady-state core inlet and outlet temperatures reported in the test data. Because contro1-rod travel was short in comparison with the 4.5-m active core length, constant differential rod worth was assumed for input to CORTAP. Core flow and inlet temperature were assumed to remain constant throughout each test. 


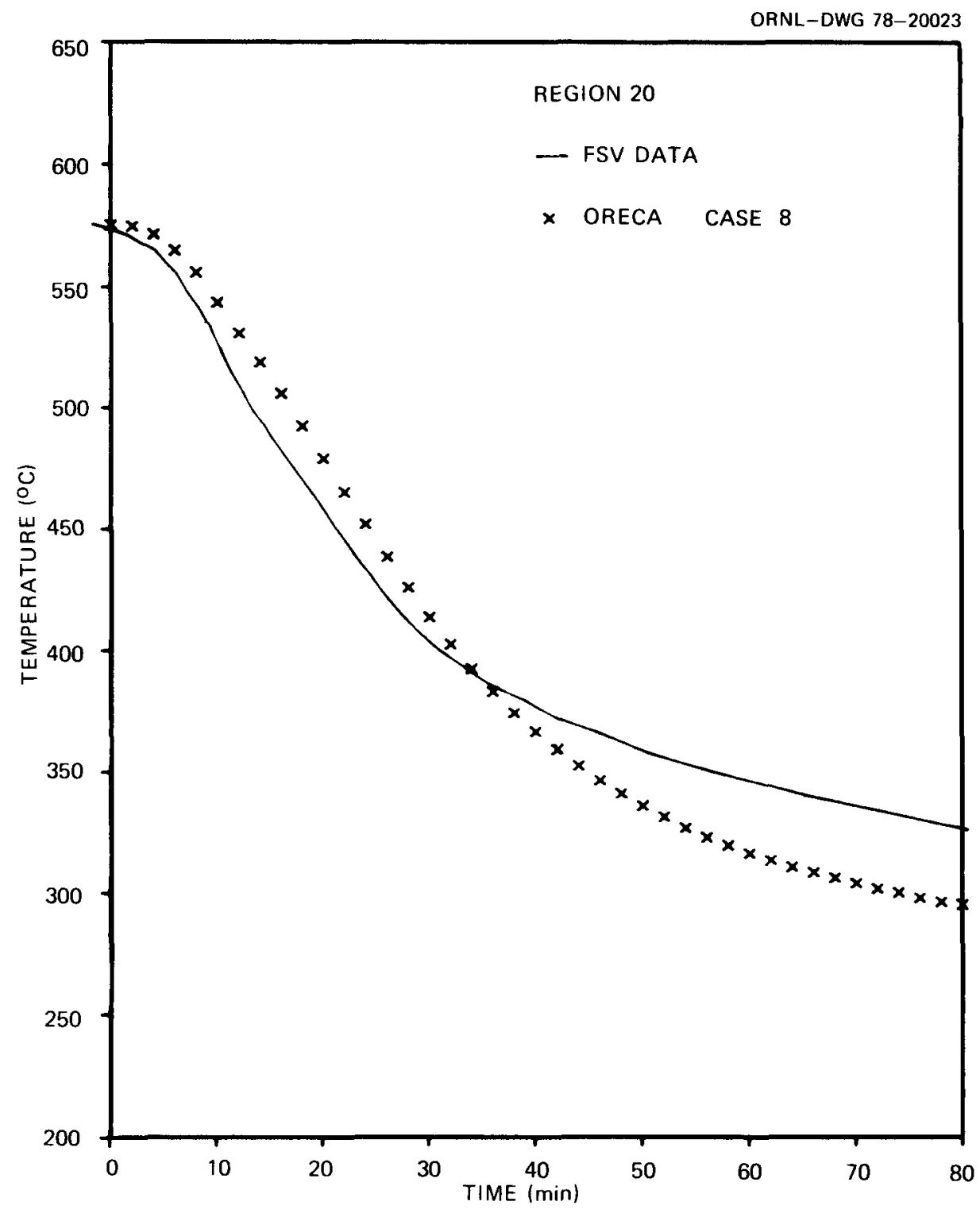

Fig. 10. FSV scram test of 0ct. 25, 1977, from $40 \%$ power - comparison of optimized ORECA code predictions of measured gas outlet temperature from region 20 vs plant data.

To set up the CORTAP code to calculate the transient, the total reactivity added by the control rods must be known; however, this was not reported for either test. By means of a sensitivity study, we found that the reactivity addition could be inferred from the data, because while the control rods are in motion, the sensitivity of the power response to contro1-rod reactivity is five to ten times greater than to any of the other parameters. After the control rods stop moving, the other parameters become more important. The fuel and moderator specific heats have an effect 
on reactor power during the dynamic part of the transient but no effect on the final steady-state power level reached. The Doppler coefficient and coolant flow have a significant effect on both the dynamic portion and final steady-state power change. If the other parameters are known reasonably we11, then the control-rod reactivity can be inferred by simply matching experimental and calculated responses during the first $6 \mathrm{~s}$ (or during the first $\sim 24 \mathrm{~s}$ for the rod insertion transient). This procedure was used to calculate control-rod reactivity for the comparisons reported.

Results of the CORTAP calculation of reactor power and the corresponding plant data are shown in Fig. 11 for the 15-cm contro1-rod withdrawa1 test. The agreement between experiment and prediction is good, both for the transient portion and for predicting the final steady-state power change. This was true of the insertion test as we11. For both rod insertion and withdrawa1, CORTAP calculated that the power change at $290 \mathrm{~s}$ would slightly undershoot the final steady-state power change. The plant data show very little tendency to undershoot the equilibrium power level. The same data were used by GA for validation of the BLOOST code, 26 with the resu1t that BLOOST predicted an undershoot very similar to the CORTAP calculations. The reason for the undershoot phenomenon remains unexp1ained; however, because the magnitude of the discrepancy is sma11, no concern that the model limitation has any safety significance exists.

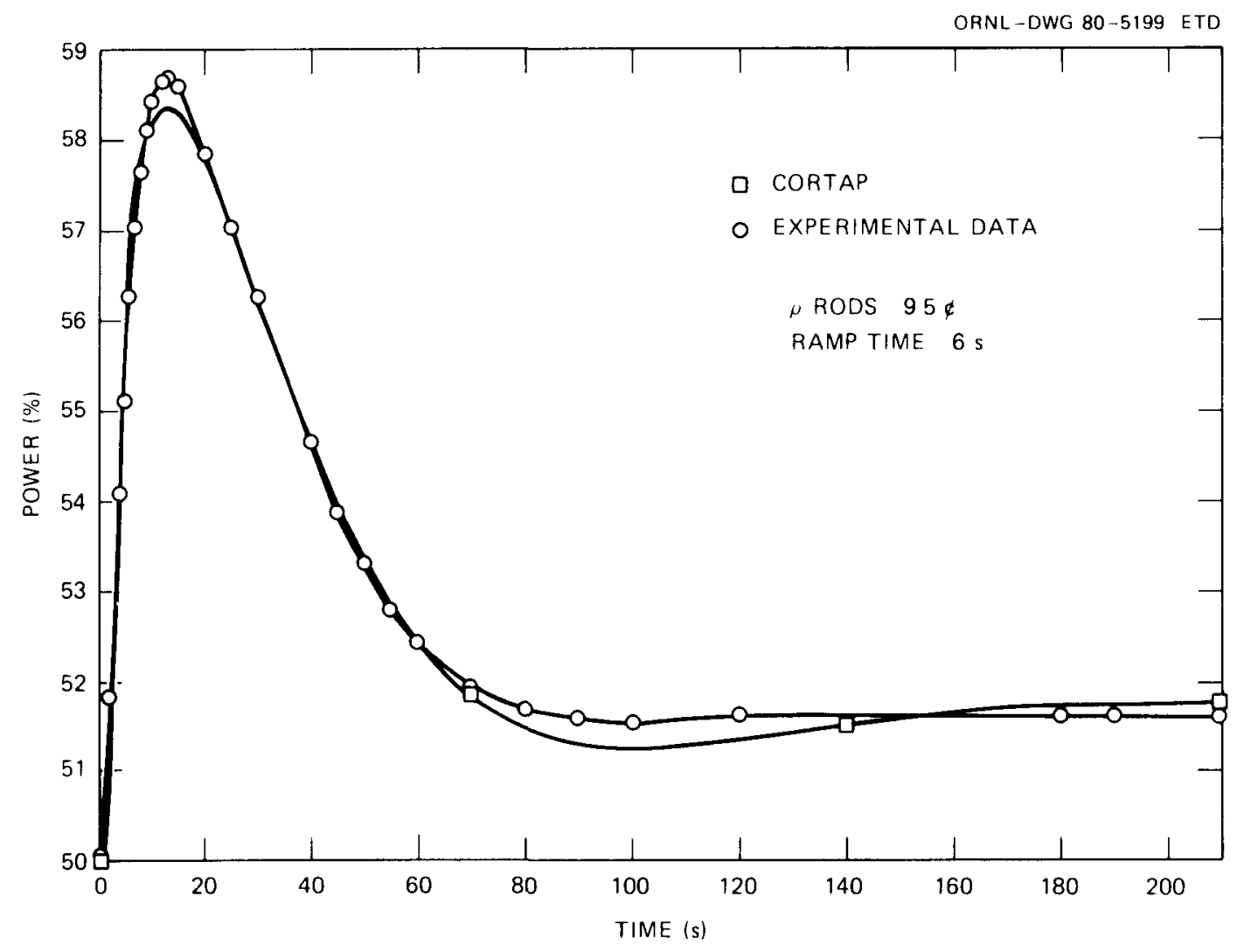

Fig. 11. Reactor power response following 9.5 c reactivity insertion. 


\subsubsection{BLAST $^{3}$}

Comparison of the BLAST code predictions with measured plant data is proceeding in two areas. The BLAST predictions were compared with FSV transient data obtained during an oscillation test transient that caused a rapid decrease in helium inlet temperature to a steam generator module in loop 1. Also, comparison of BLAST predictions with data obtained from the AVR steam generator were made in 1980. (More information on this effort is given in Sect. 4.7.)

The FSV oscillation test transient of November 4, 1978, involved a large [ $\left.44^{\circ} \mathrm{C}\left(80^{\circ} \mathrm{F}\right)\right]$ rapid decrease in helium inlet temperature to one of the 12 steam generator modules (B-1-1 in loop 1) and resulted in a drop in main steam subheader temperature of $\sim 68^{\circ} \mathrm{C}\left(122^{\circ} \mathrm{F}\right)$ for this module. The purpose of this analysis was to make a direct comparison of BLAST predictions with the measured plant response. Analysis of the transient is not complete, but the following is intended to indicate the nature of the preliminary results obtained to date.

For the oscillation transient, GA provided measured data for reactor power, loop 1 feedwater flow, total core helium flow, module B-1-1 helium inlet temperature, loop 1 inlet and outlet reheat-steam temperature, and modn1e B-1-1 subheader outlet steam temperature vs time. Some inputs required for BLAST (e.g., feedwater temperature and pressure, reheat-steam flow and pressure, and main steam pressure) were not provided and have been estimated by interpolating from steady-state conditions expected at 25 and $100 \%$ power. Additionally, $100 p 1$ feedwater flow and reheat-steam flow were assumed to be distributed equally among the six stean generator modules in loop 1 .

The model used in analyzing this transient uses ten water nodes, ten tube nodes, and seven helium nodes.

Figure 12 shows a comparison of the change in exit steam temperature from the main superheated steam section (superheater II) as computed by BLAST vs the change in measured subheader outlet temperature for module B-1-1.* The flow-dependent $19 \mathrm{~g}$ associated with the steam temperature measurement has been incorporated into the BLAST prediction. As is shown, the calculated drop in steam temperature resulting from the $44^{\circ} \mathrm{C}$ drop in helium inlet temperature was $\sim 67^{\circ} \mathrm{C}\left(121^{\circ} \mathrm{F}\right)$ and compares very well with measured steam temperature drop. However, the measured data showed that the initial drop in steam temperature was followed by a $25^{\circ} \mathrm{C}\left(45^{\circ} \mathrm{F}\right)$ increase in steam temperature, which is not reflected in the BLAST calculations. The increase may result from differences between actual conditions (e.g., transient feedwater flow, feedwater inlet temperature, and main steam pressure for module $B-1-1$ ) and estimated input to BLAST (the estimated values used in BLAST for these parameters were assumed to remain constant during the transient). Furthermore, while the computed temperature changes during the transient compare fairly well with measured data, an offset occurs at the time of transient initiation between the computed superheater-II exit temperature and the measured subheader temperature of $\sim 42^{\circ} \mathrm{C}\left(75^{\circ} \mathrm{F}\right.$ ) (based on current inputs to BLAST, some of which are assumed values), with the computed temperature higher than the measured value.

* Superheater II exit temperature is not measured for module B-1-1. 


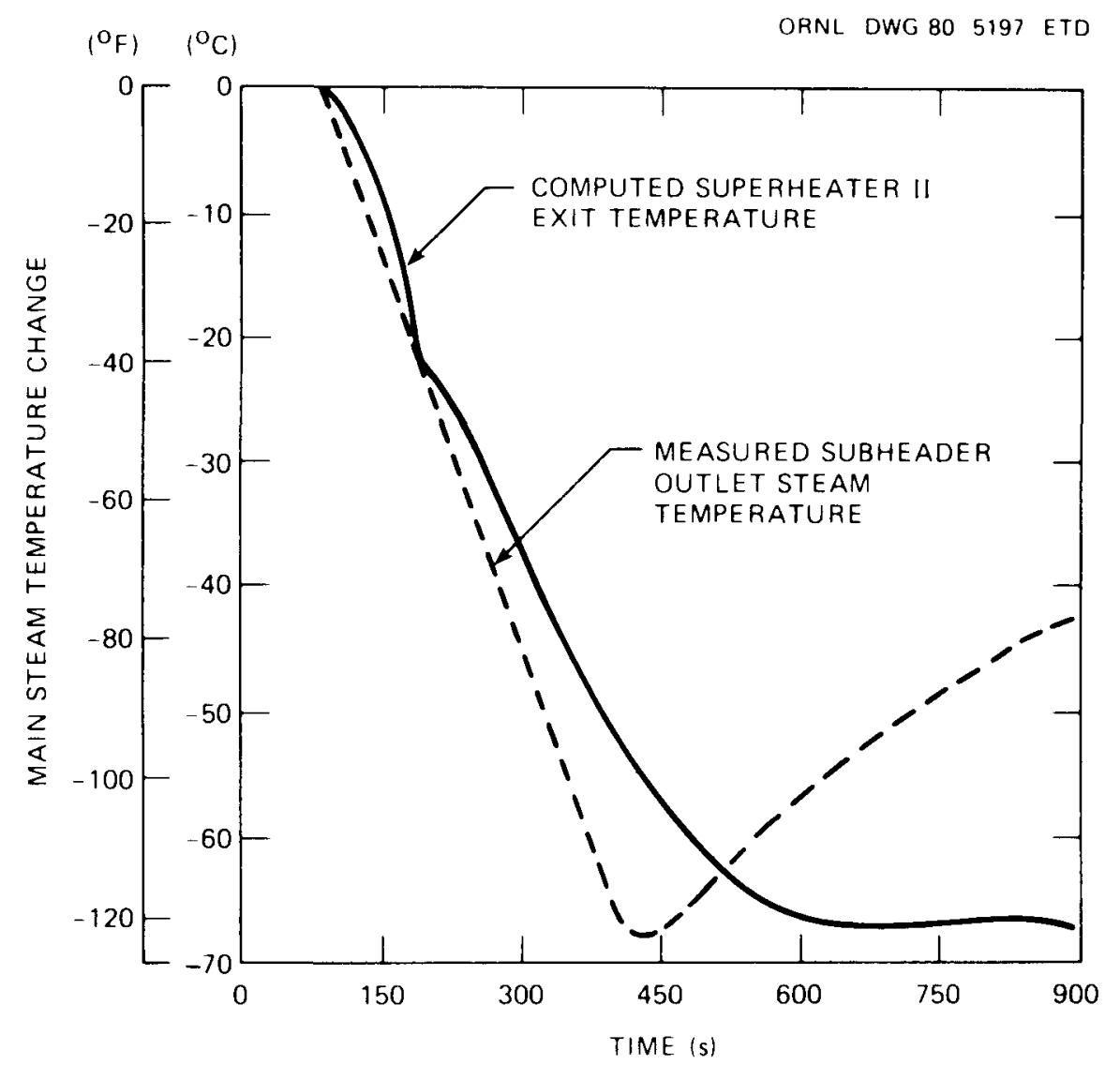

Fig. 12. Comparison of computed superheater II exit steam temperature with measured subheader outlet steam temperature for module $B-1-1$.

Reasons for this offset have not been explored in depth to date. A significant portion of this offset could possibly be attributed to regenerative heating, which causes the subheader-outlet main steam temperatures to be lower than superheater II exit temperatures. Another likely source of error is the omission of reheater attemperation flow from the mode1. Adding attemperation would decrease the calculated superheater helium inlet temperature and thus lower the steam exit temperature.

The first step in examining the reasons for the differences between the preliminary BLAST computation and measured data for the oscillation transient is to attempt to obtain data for those input values that have had to be estimated for these initial BLAST calculations. Specifically, data are needed for (1) feedwater inlet temperature, pressure, and f1ow (to module B-1-1), (2) main steam pressure, and (3) reheat-steam flow and pressure during the transient.

\subsection{HTGR Safety Information Foreign Exchange Programs}

The ORNL program has had the good fortune to benefit significantly from two foreign exchange programs. A guest scientist from Japan, 
M. Hatta, was sponsored by his home company (IHI) and Japan Atomic Energy Research Institute for a one-year visit to ORNL to work on the RSRsponsored program (July 1977 to June 1978). Mr. Hatta brought with him a wealth of experience relevant to HTGR safety and made numerous and substantial contributions to our program. Other significant benefits resulted from attendance (by $S$. J. Ba11) at the HTGR Safety Technology Conference ${ }^{2}$ in Fuji, Japan, in November 1978, and the subsequent information exchange that resulted from the trip.

The RSR program has also had a number of useful exchanges with the West Germans. Initial1y, RWTUV acquired the BLAST code and ORTAP for use in their licensing studies of the THTR. Since then, ORNL and RWTUV have had much fruitful correspondence, and several RWTUV-developed improvements have been incorporated into BLAST. More recent1y, one of the ORNL program staff members received a one-year assignment to KFA in Jülich to work on HTGR safety problems.

Regular correspondence and information exchanges have also been set up with British [Central Electricity Generating Board (CEGB)] as well as Japanese and German HTGR researchers.

\subsection{Investigations of Overheating of FSV Upper-Plenum Cover Plates During Extended LOFC Accidents}

A major uncertainty in the prediction of the consequences of sustained LOFC accidents in HTGRs is the effective heat transfer from the heated (upflow) plumes from the core refueling regions to the therma1barrier cover plates lining the top of the upper plenum. The reverse corecoolant flow phenomenon occurs because of the buoyancy of hot $g$ as in a refueling region and is typically significant only when the reactor is at or near its full pressure of $\sim 4.8 \mathrm{MPa}$ (700 psia). Reverse flows normally occur in the higher-peaking-factor regions. The problem is especially significant in the FSV upper plenum, which has carbon steel cover plates with a maximum temperature 1 imit of $\sim 815^{\circ} \mathrm{C}\left(1500^{\circ} \mathrm{F}\right)$. Simulations of 2-h LOFC accidents have indicated that this temperature 1 imit might be exceeded, depending largely on the assumptions of plume heat transfer.

A search of the 1 iterature and consultations with experts in the field indicated that no experimental data are available that would be directly applicable to the HTGR LOFC case. Consequently, two approaches were considered: (1) conduct special reverse flow tests at FSV and (2) develop a low-temperature air model experiment that could simulate the high-temperature high-pressure helium. Plans for possible FSV tests are still in the preliminary planning stage.

The testing with a scaled low-temperature, low-pressure air model of the actual FSV upper plenum during an LOFC would have to be based on the assumption that certain scaling laws would apply. The object, then, was to scale the model such that both the Reynolds and Grashof numbers would be roughly equivalent. Such a comparison is shown in Table 4.

Preliminary scoping tests of a scaled air model were run initially. Subsequently, a small-scale plume experiment was built and tested (Fig. 13). The purpose of the experiment was to demonstrate the applicability of the assumed scaling laws and iron out procedural and measurement problems that would be encountered in a ful1-scale mode1. 
Tab1e 4. Comparison of HTGR plume and air mode 1 parameters

\begin{tabular}{|c|c|c|}
\hline Parameters & $\begin{array}{c}\text { HTGR helinm } \\
\text { plume }\end{array}$ & $\begin{array}{l}\text { Mode1 air } \\
\text { plume }\end{array}$ \\
\hline Temperature, ${ }^{\circ} \mathrm{C}\left({ }^{\circ} \mathrm{F}\right)$ & $1093(2000)$ & $93(200)$ \\
\hline Pressure, $\mathrm{MPa}$ (psia) & $4.8(700)$ & $0.1(14.7)$ \\
\hline Density, $\mathrm{kg} / \mathrm{m}^{2}\left(1 \mathrm{~b} / \mathrm{m} / \mathrm{ft}^{3}\right)$ & $1.76(0.11)$ & $0.96(0.06)$ \\
\hline Viscosity, $\mathrm{kg} / \mathrm{ms}\left(1 \mathrm{~b}_{\mathrm{m}} / \mathrm{ft} \cdot \mathrm{h}\right)$ & $5.8 \times 10^{-3}(0.14)$ & $2.2 \times 10^{-5}(0.053)$ \\
\hline Mass flow, $\mathrm{kg} / \mathrm{s}\left(1 \mathrm{~b}_{\mathrm{m}} / \mathrm{min}\right)$ & $0.11(15)$ & $0.045(5.9)$ \\
\hline $\begin{array}{l}\text { Equivalent orifice diameter, } \\
\text { m (in.) }\end{array}$ & $0.43(17)$ & $0.43(17)$ \\
\hline Velocity, $\mathrm{m} / \mathrm{s}$ (fps) & $0.46(1.5)$ & $0.32(1.04)$ \\
\hline Reynolds No. & 6000 & 6000 \\
\hline Grashof No. & $7 \times 10^{8}$ & $4.3 \times 10^{8}$ \\
\hline
\end{tabular}

In the test, a rotameter measures air flow through a heater assembly and into a nozzle with adjustable diameters, which directs the heated air up to a thin flat plate mounted above and representing an FSV upper-plenum cover plate. Mounted in the plate is a thin metal can insulated on the top and sides and partially filled with water that serves as a calorimeter to measure the rate at which heat from the plume is transferred to the plate area. The height of the plume, as well as its (nozzle) temperature and flow, are all adjustable. Material considerations limit the nozzle temperature to $\sim 315^{\circ} \mathrm{C}\left(600^{\circ} \mathrm{F}\right)$. A curtain is used to shield the plume from extraneous drafts.

An on-1ine computer is used to monitor temperatures of the p1ume, calorimeter water, and ambient air and to calculate the heat transfer rate, heat transfer coefficients (Nusse1t numbers), Reynolds number at the nozzle, the Grashof number, and other data that indicate the statistical accuracy (confidence level for a prescribed accuracy or error tolerance). The program written to acquire and analyze the data is set up to contro1 the duration of the run based on the run statistics.

An example set of results of several runs on the reverse-flow plume experiment with a nominal nozzle exit temperature of $205^{\circ} \mathrm{C}\left(400^{\circ} \mathrm{F}\right)$ and a $0.305-m(12-i n$.$) plume height are shown in Fig. 14. Of these runs, the$ two that are classified as variant runs, 6 and 8 , are characterized by both higher-than-average values of Nusset and higher plume-top temperatures. This variation is postulated to be caused by a basic plume instability problem; that is, under similar conditions of nozzle exit temperature and flow, plume height, and ambient temperature, quasi-stable plumes could be established with significantly different top temperatures and 
ORNL-DWG 79-17057 ETD

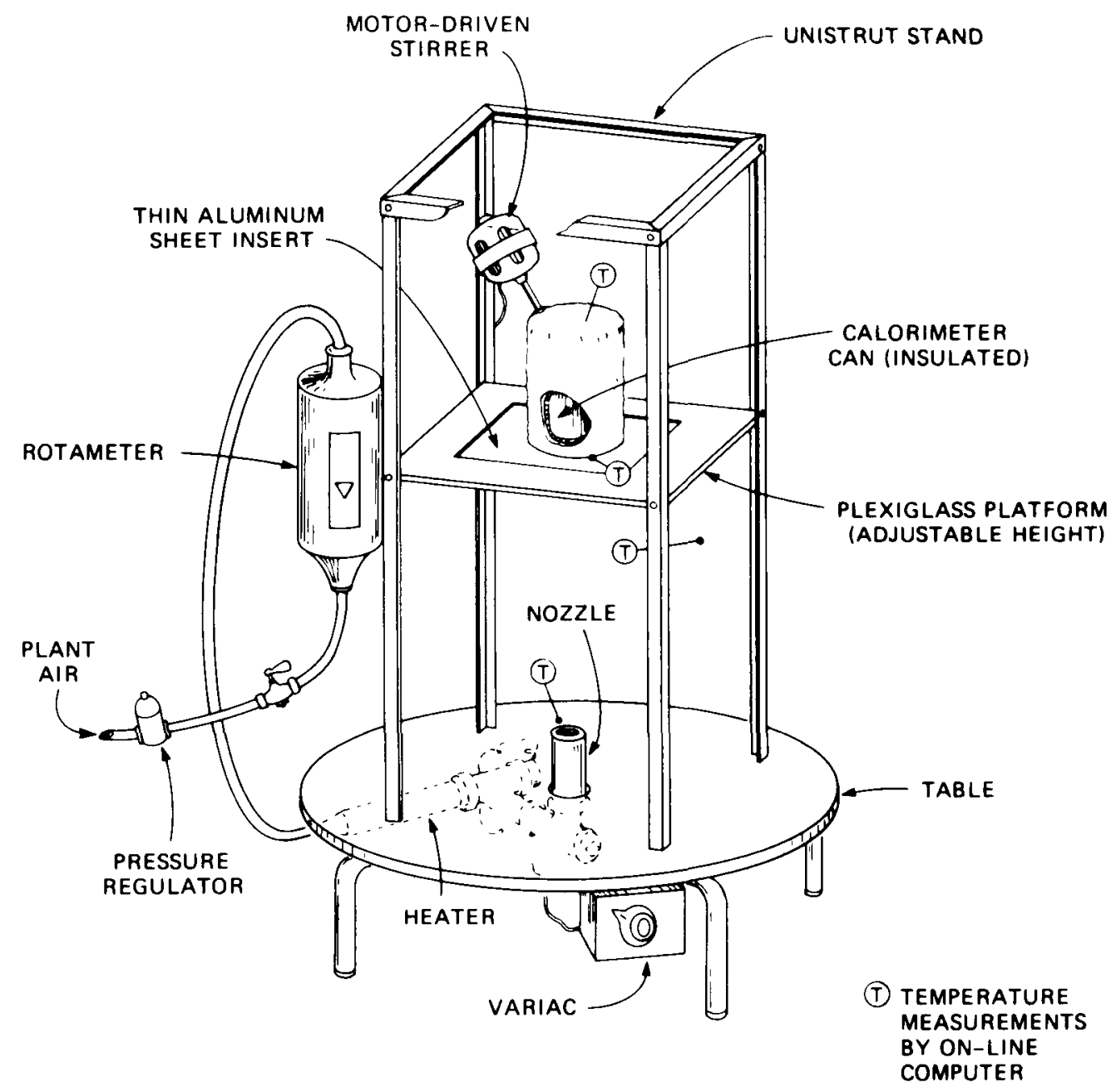

Fig. 13. Sma11-scale heated-plume experiment assembly.

rates of heat transfer to the calorimeter. The instability is believed to be related to the extent of the mixing of the hot plume with the surrounding ambient air.

Several other more qualitative tests showed that exposing the plume to nearly still ambient air by opening the protective curtain would essentially destroy the plume, even for relatively short plume heights and typical accident-case nozle velocities. Therefore, we may postualate that more subtle plume disturbances could occur even within the protective shroud of the curtain, which could result in the formation of quasistable plumes. (In all cases, the plume-top temperatures were quite stable over the data-taking period, $\sim 1 / 2$ h.)

General Atomic Company postulated that the plumes established following an LOFC accident at FSV would be we11 mixed; therefore, a mixed mean 
ORNL-DWG 80-4457 ETD

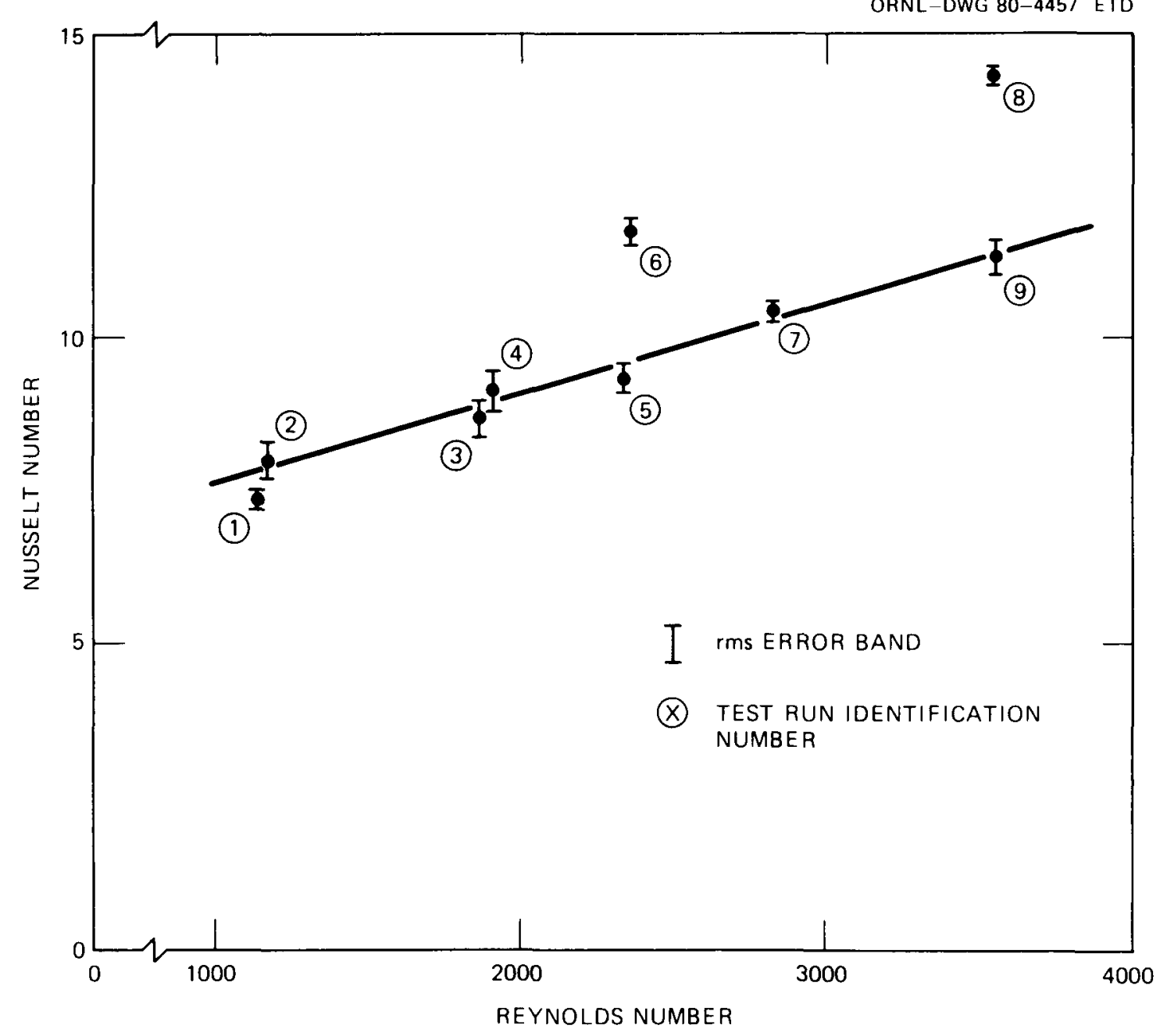

Fig. 14. FSV plume tests with nozzle temperature of $\sim 205^{\circ} \mathrm{C}\left(\sim 400^{\circ} \mathrm{F}\right)$ and plume height of $0.305 \mathrm{~m}$ (12 in.), November 1979.

upper-plenum gas temperature, rather than individual hot p1ume temperatures, should be used in the prediction of cover plate temperatures.

The conclusions drawn from these observations were that (1) the mixing of adjacent plumes in the FSV upper plenum, where plumes would have no protective shrouds, is expected to be large and thus help to substantiate GA's claim; and (2) these apparent plume instabilities would make difficult the conclusive demonstration of the applicability of the similarity laws for Reynolds and Grashof scaling. Such a demonstration depended on obtaining the same values of Nusselt for given values of Reynolds, Grashof, and H/D, the plume height-to-nozzle-diameter ratio; typically, the tests showed no such relationships. The model testing was therefore abandoned, and the conclusion was that upper-plenum plume instabilities would make cover plate damage during the postulated LOFC unlikely. 


\subsection{Calculations of Postulated FSV Reactor LOFC/FWCD Accidents for Core Therma1 Stress Evaluations}

Results of previous analyses of the postulated design-basis earthquake LOFC accident followed by an FWCD were used by LANL to calculate thermal stresses in parts of the core-support structure. These stresses result from large temperature differences between adjacent refueling regions caused by preferential heating and cooling of the regions during the LOFC and FWCD phases of the accident. Recent LANL calculations of maximum stresses in the core-support blocks indicated that the stresses were large enough for some concern about possible crack formation and propagation in the support blocks. Several significant uncertainties, however, in both the thermal analyses (ORECA code) and the stress analyses (LANL calculations) required refinements in both analyses.

Sensitivity studies were completed using the ORECA code to determine the effect of changes in the reference-case assumptions. These studies indicated that a reduction of initial core power and an increase in the firewater booster pump output could significantly reduce the maximum region-to-region temperature difference. The reference-case analyses had been done assuming a $105 \%$ operating power leve1; thus, further analyses at the current FSV operating 1 imit $(\sim 70 \%)$ were recommended as an interim means of alleviating concern about the safety of present operation, at least until more detailed analyses of the ful1-power case were available. Booster pump tests had shown that the FWCD flow estimates used in the analysis were conservative. The sensitivity studies also showed that the problem was less severe for high-flow-resistance cores because the redistribution of the coolant flow in the FWCD phase is less sensitive to the hot coolant-channel flow resistance.

Further refinements to the ORECA code in the core-support region were a1 so found to be needed to provide more detailed information for LANL's stress analysis code inputs. Output was sent to LANL from a revised ORECA model that had ten axial nodes per refueling region - one for the upper reflector, one for each of the six fueled regions, two equal-sized nodes for the bottom reflector, and one for the core-support block. The revised ORECA version also provided outputs of heat flows into selected nodes via conduction and convection. 


\section{HTGR SAFETY GOALS}

\subsection{Near-Term Safety Goa1s}

A11 HTGR near-term safety goals deal primarily with safety issues related to the operation and licensing of the FSV reactor. The most current and important of these is the technical support and assistance to the NRC NRR 1icensing staff on specific licensing questions. Recent assistance has concerned approval of PSC's request to operate FSV up to $100 \%$ power. Specifica11y, the program provided input on (1) questions of excessive thermal stresses in the core-support regions following a postulated design-basis earthquake accident, (2) GA RECA code verification analyses after installation of the region constraint devices, and (3) adequacy of the proposed PSC test plans (RT-500K) for oscillation testing between 70 and $100 \%$ power. Some follow-up work and post-test analyses are expected on 11 but the thermal stress issue.

Other near-term safety goals that we have proposed to NRC include the following:

1. FSV experiments and analyses to resolve questions about core bypassflow fraction, hot streak phenomena, and region reverse flow behavior;

2. analyses and tests of interaction between the control and safety system;

3. tests of region-outlet thermocouple dynamic response (to resolve questions about identification of safety-related parameters from test data); and

4. consideration of SASA similar to those being addressed in the LWR safety programs.

\subsection{Long-Term Safety Goals}

The longer-term safety goals deal more with generic HTGR problems, which in turn depend on the status of the DOE-sponsored development programs. Present1y, the status of DOE funding is uncertain, so setting priorities for longer-range safety work is difficult. Of the advanced HTGR concepts, those that generate process heat as well as electrical output appear most 1ike1y to succed; therefore, new safety problems will relate to dealing with higher (process heat) temperatures, both for steady-state operation and accident transients, and with more complex system interaction and interdependence that result from having a process heat system coupled to the reactor primary coolant loops.

Specific areas in which longer-term HTGR safety work would be appropriate are:

1. environmental release - thermal discharge and radioactivity discharge;

2. safeguards [strategic nuclear materia1s (SNM) diversion)]; and

3. the risk to population from plant accidents - safety systems reliability, inherent plant safety features, normal plant equipment reliability, and the ability of containment to withstand and contain radioactivity from severe core damage. 
For a given proposed advanced plant design, a good way to categorize potential safety issues is to make a list of accidents or types of accidents that should be considered. Calculations are then performed using computer models as necessary to determine if the proposed reference plant is likely to be able to meet the desired safety goals. On completion of this task, the researcher can specify ways in which the plant may be deficient for a given type of accident, and also what types of design modifications would be required to meet the safety goals.

The key to acceptability will be an assessment of the risk to the general population. This will require not only the calculation of the failure probabilities of plant equipment, but also deterministic calculation of the consequences of accidents resulting from plant failures. In a long-range program of safety research, risk assessment should be conducted for a variety of design alternatives to firmly establish regulatory requirements for future HTGR plants.

To be able to perform the risk assessment task mentioned above, the NRC safety researchers should have good analytical tools - computer programs that allow accurate prediction of the consequences of postulated accidents. Predicting (without further study) everything that will have to be calculated via computer models is impossible, but a logical assumption is that safety analysis research will have to concentrate on accidents that can have severe consequences.

The types of events that the computer codes will need to be able to handle include the following:

1. loss of forced circulation,

2. loss of coolant (leakage of helium or steam),

3. Loss of process gas (if applicable),

4. excessive reactor core heat-up,

5. failure of normal and/or safety systems to operate as designed, and

6. water and other impurity ingress into the primary system.

The basic task of most of the system models will be calculation of pressures, temperatures, and flow rates by solution of the equations for conservation of mass, energy, and momentum. To complete the therma1hydraulic calculation, in some accidents the ability to predict the chemical reactions that an HTGR core can undergo when exposed to unusual atmospheres will be necessary. For this example, however, use of only the basic conservation relations is insufficient, and the results of laboratory experimentation will have to be factored into the computer models. If applicable experimental data are not available, then one output of the safety assessment would be a recommendation that laboratory testing be performed to develop the needed data.

Examples of specific calculational capabilities required for the advanced HTGRs include the following:

1. very-high-temperature fuel behavior, including chemical behavior when exposed to air or water vapor, and radioactivity release;

2. PCRV cooling systems (for total loss of heat sink events);

3. post-accident radioactivity transport;

4. containment response (where applicable); and

5. process gas combustion or explosion. 
In summary, development of computer mode1s for HTGR safety research clearly should be coupled with a sincere effort to find out what major safety issues 1 ie in the way of future licensing of HTGRs. This research will assure that the computer models developed will have all the capabi1ity required to help in the resolution of the important safety issues.

\subsection{Possible Application of an ORNL Experimental Facility, the CFTL, to HTGR Safety Problems}

The original design of the core flow test loop (CFTL) was developed for and funded by the DOE gas-cooled fast reactor (GCFR) program to test simulated fuel bundles in a high-temperature, high-pressure helium environment. Following the cancellation of the GCFR program in 1980, the CFTL construction was completed by DOE funding to make it available as an HTGR component flow test loop (also CFTL). The CFTL is a closed-circuit helium circulating system designed with a variable electrical heat supply and an air-cooled heat sink, capable of both steady-state and transient operation over a wide range of temperatures and pressures. It is also provided with a large and powerful on-1ine data acquisition and computer system, as wel1 as a direct digital computer control system. A flow diagram of the CFTL is shown in Fig. 15. Potential HTGR safety applications presently under consideration of the CFTL include testing of primary-loop heat exchange

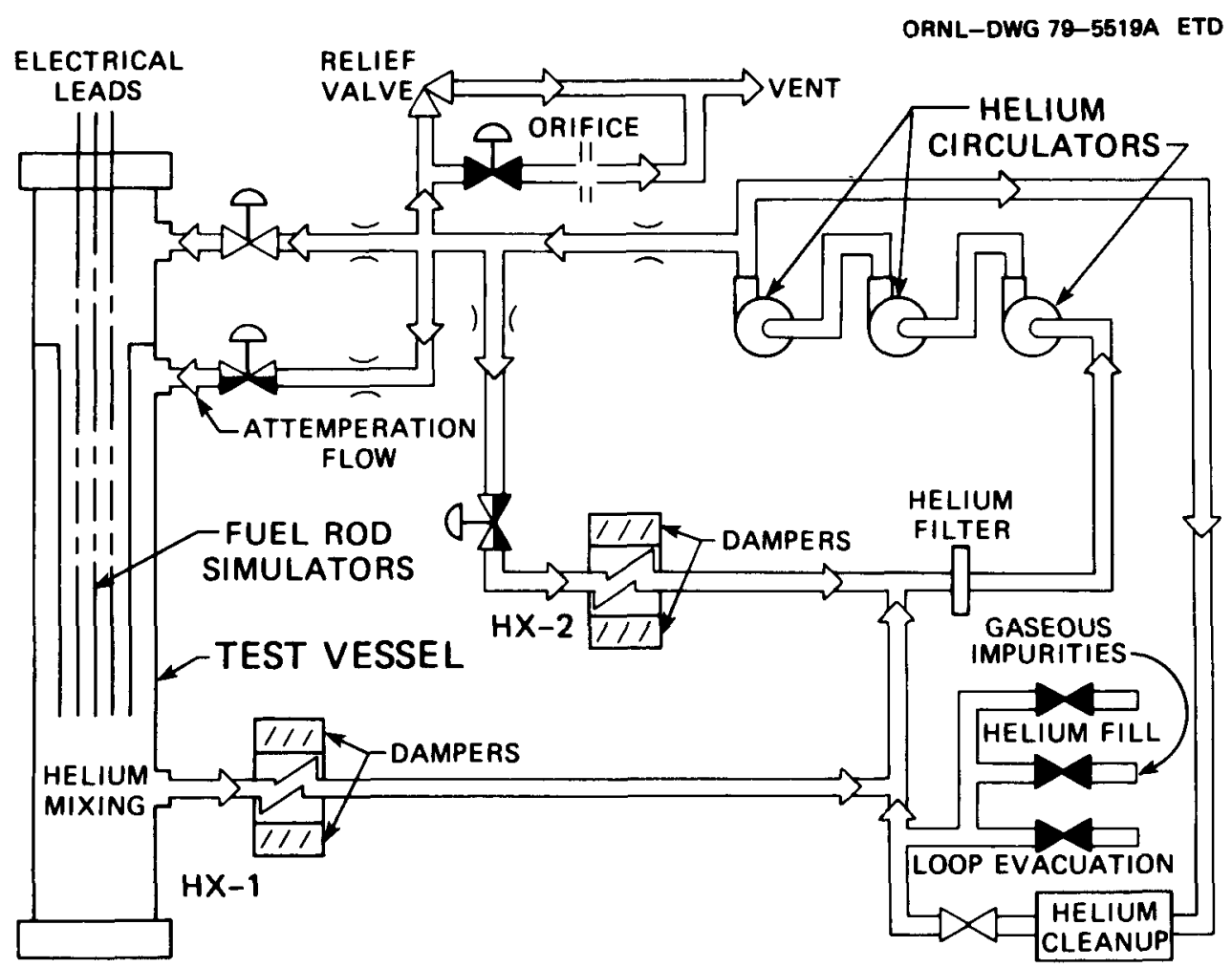

Fig. 15. Flow diagram - CFTL. 
equipment and core cavity component performance. The major characteristics of the CFTL are as follows:

1. design pressure - $11.8 \mathrm{MPa}(1715 \mathrm{psia})$;

2. operating pressure - ambient to $10.6 \mathrm{MPa}(1540$ psia);

3. power - 0 to $4 \mathrm{MW}$, controlled by 13 independent power supplies;

4. temperature -260 to $600^{\circ} \mathrm{C}$. At temperation flow arrangement allows stainless steel melting $\left(\sim 1350^{\circ} \mathrm{C}\right)$ in the test section;

5. transient - full power to zero power in $1 \mathrm{~s}$, full flow to zero flow in $1 \mathrm{~s}$, fully pressure to approximate1y ambient in 1 ess than 1 min. Al1 transients fully program controlled;

6. helium circulators - centrifugal type with gas-1ubricated bearings, hermetically sealed;

7. working media - designed for helium with impurity control;

8. flow rate - 0 to $3.2 \mathrm{~kg} / \mathrm{s}$ (circulators in series), to $9.6 \mathrm{~kg} / \mathrm{s}$ (circulators in paralle1);

9. flow measurement - wide range, high-accuracy vortex shedding flow meters;

10. data acquistion - high-speed $(10 \mathrm{kHz}), 640$ channels (expandable), computer controlled;

11. 1ocation - Building 9201-3, Y-12 P1ant, Oak Ridge, Tennessee 37830;

12. operator - Engineering Technology Division, ORNL;

13. sponsor - DOE, GCFR program (former1y), HTGR program (currently); and

14. availability - second half of 1981 (partial capability). 


\section{REFERENCES}

1. Oak Ridge National Laboratory, Planning Guide for HTGR Safety and Safety-Related Research and Development, ORNL-4968 (May 1974).

2. Division of Reactor Safety Research, NRC, Program Plan for Confirmatory HTGR Safety Research, Preliminary Draft (Feb. 28, 1975).

3. Peter G. Kroeger, ORECA Code Assessment, BNL-NUREG-28707 (Ju1y 1980).

4. S. J. Ball et a1., Evaluation of the General Atomic Codes TAP and RECA for HTGR Accident Analyses, ORNL/NUREG/TM-178 (May 1978).

5. A. Bardia and R. C. Potter, TAP: A Program for Analysis of HTGR Nuclear Steam Supply System Performance Transients, GA-A-13248 (Jan. 30, 1976).

6. J. F. Petersen, RECA3: A Computer Code for Thermal Analysis of HTGR Emergency Cooling Transients, GA-A-14520 (August 1977).

7. J. C. Cleveland, CORTAP: A Coupled Neutron Kinetics-Heat Transfer Digital Computer Program for the Dynamic Simulation of the High-

Temperature Gas-Cooled Reactor Core, ORNL/NUREG/TM-39 (January 1977).

8. R. A. Hedrick and J. C. Cleveland, BLAST: A Digital Computer Program for the Dynamic Simulation of the High-Temperature Gas-Cooled Reactor Reheater-Steam Generator Module, ORNL/NUREG/TM-38 (August 1976).

9. J. C. Cleveland et a1., ORTAP: A Nuclear Steam Supply System Simulation for the Dynamic Analysis of High Temperature Gas Cooled Reactor Transients, ORNL/NUREG/TM-78 (September 1977).

10. J. C. Cleveland et a1., "ORTAP: A Simulator of High Temperature GasCooled Reactor Nuclear Steam Supply System Dynamics," pp. 359-69 in Proceedings of the 1977 Summer Computer Simulation Conference, July $18-20$, 1977 , Simulation Councils, Inc.

11. S. J. Ba11, ORECA-I: A Digital Computer Code for Simulating the Dynamics of HTGR Cores for Emergency Cooling Analyses, ORNL/TM-5159 (April 1976).

12. S. J. Ba11 et a1., High-Temperature Gas-Cooled Reactor Safety Studies for the Division of Reactor Safety Research Quart. Prog. Rep., Jan. 1-March 31, 1977 , ORNL/NUREG/TM-115.

13. S. J. Ba11 and R. K. Adams, MATEXP: A General Purpose Digital Computer Program for Solving Ordinary Differential Equations by the Matrix Exponential Method, ORNL/TM-1933 (August 1967). 
14. S. J. Ba11 et a1., High-Temperature Gas-Cooled Reactor Safety Studies for the Division of Reactor Safety Research Quart. Prog. Rep., AprilJune 30, 1979, ORNL/NUREG/TM-356.

15. T. W. Ker1in, HTGR Steam Generator Modeling, ORNL/NUREG/TM-16 (Ju1y 1976).

16. J. C. Conk1in, ORTURB - A Digital Computer Code to Determine the Dynamic Response of the Fort St. Vrain Reactor Steam Turbines, ORNL/ NUREG/TM-399 (March 1981).

17. J. G. Delene, A Digital Computer Code for Simulating the Dynamics of Demonstration Size Dual-Purpose Desalting Plants Using a Pressurized Water Reactor as a Heat Source, ORNL/TM-4104 (September 1973).

18. D. D. Pau1, FLODIS - A Computer Model to Determine the Flow Distribution and Thermal Response of the Fort St. Vrain Reactor, ORNL/TM-5365 (June 1976).

19. S. J. Bal1 et a1., High-Temperature Gas-Cooled Reactor Safety Studies for the Division of Reactor Safety Research, Quart. Prog. Rep., Jan. 1-March 31, 1979 , ORNL/NUREG/TM-336.

20. Public Service Company of Colorado, Final Safety Analysis Report, Fort St. Vrain Reactor Docket No. 50-267.

21. J. C. Cleveland et a1., "Simulation of the Response of the Fort St. Vrain High-Temperature Gas-Cooled Reactor System to a Postulated Rod Withdrawa 1 Accident," pp. 318-36 in Proceedings of ANS Topical Meeting on Thermal Reactor Safety, Sun Valley, ID., July 31-Aug. 4, 1977 , V.2, American Nuclear Society.

22. S. J. Ba11 et a1., High-Temperature Gas-Cooled Reactor Safety Studies for the Division of Reactor Safety Research, Quart. Prog. Rep.. Oct. 1-Dec. 31, 1977, ORNL/NUREG/TM-164.

23. Letter from S. J. Ba11, ORNL, to R. D. Schamberger, NRC, Evaluation and Confirmation of ECCS Analyses for the Fort St. Vrain Reactor: "Immediate Tasks," May 25, 1978.

24. S. J. Ba11, "Dynamic Mode1 Verification Studies for the Therma1 Response of the Fort St. Vrain HTGR Core," pp. 15-1-15-12 in Proceedings of 4th Power Plant Dynamics, Control and Testing Symposium, Gatlinburg, Tennessee, March 17-19, 1980, University of Tennessee College of Engineering, University of Tennessee.

25. S. J. Ba11 et a1., High-Temperature Gas-Cooled Reactor Safety Studies for the Division of Reactor Safety Research, Quart. Prog. Rep., Jan. 1-March 31, 1980, ORNL/NUREG/TM-397.

26. M. Merrill and M. Troost, BLOOST-5: A Combined Reactor KineticsHeat Transfer Code, GAMD-6644 (August 1965). 
27. S. J. Ba11 et a1., "Investigations of Postulated Accident Sequences for the Fort St. Vrain HTGR," pp. 6-1-6-12 in Proc. 2nd U.S.-Japan Seminar on HTGR Safety Technology, Nov.24-25, 1978, Fuji Japan, Vol. I., JAERI. 
NUREG / CR-2392

ORNL/TM-8073

Dist. Category R8

INTERNAL DISTRIBUTION

1-5. S. J. Ba 11

6-10. J. C. C1eveland

11-15. J. C. Conk1 in

16. J. G. Delene

17-21. R. M. Harrington

22. D. N. Fry

23. P. R. Kasten

24. A. L. Lotts

25. D. L. Moses

26. T. W. Robinson, Jr.

27. J. P. Sanders

28. R. S. Stone
29. L. C. Oakes

30. T. S. Kress

31. I. Spiewak

32. N. E. Clapp

33. D. N. Fry

34. H. E. Tramme 11

35. ORNL Patent office

36. Central Research Library

37. Document Reference Section

38-39. Laboratory Records Department

40. Laboratory Records (RC)

EXTERNAL DISTRIBUTION

41-44. Director, Office of Nuclear Regulatory Research, USNRC, Washington, DC 20555

45. Acting Chief, Advanced Safety Technology Branch, Division of Reactor Safety Research, Office of Nuclear Regulatory Research, USNRC, Washington, DC 20555

46. Director, Reactor Division, DOE, ORO, Oak Ridge, TN 37830

47. Office of Assistant Manager for Energy Research and Development, DOE, ORO, Oak Ridge, TN 37830

48-49. Technical Information Center, DOE, Oak Ridge, TN 37830

50-329. Given distribution as shown in category R8 (10-NTIS) 